Article

\title{
Life-Cycle Assessment of Fly Ash and Cenosphere-Based Geopolymer Material
}

\author{
Weixin Tang ${ }^{1}$, Gloria Pignatta ${ }^{1,2, *(D)}$ and Samad M. E. Sepasgozar ${ }^{1}$ (D) \\ 1 Faculty of Arts, Design, and Architecture, School of Built Environment, University of New South \\ Wales (UNSW) Sydney, Kensington, Sydney 2052, Australia; raymond141996@gmail.com (W.T.); \\ sepas@unsw.edu.au (S.M.E.S.) \\ 2 Material and Manufacturing Future Institute (MMFI), University of New South Wales (UNSW) Sydney, \\ Kensington, Sydney 2052, Australia \\ * Correspondence: g.pignatta@unsw.edu.au
}

Citation: Tang, W.; Pignatta, G.; Sepasgozar, S.M.E. Life-Cycle Assessment of Fly Ash and Cenosphere-Based Geopolymer Material. Sustainability 2021, 13, 11167. https: / / doi.org/10.3390/ su132011167

Academic Editors: Elie Azar, Mounir El Asmar and Marc A. Rosen

Received: 3 August 2021

Accepted: 5 October 2021

Published: 10 October 2021

Publisher's Note: MDPI stays neutral with regard to jurisdictional claims in published maps and institutional affiliations.

Copyright: (c) 2021 by the authors. Licensee MDPI, Basel, Switzerland. This article is an open access article distributed under the terms and conditions of the Creative Commons Attribution (CC BY) license (https:// creativecommons.org/licenses/by/ $4.0 /)$.

\begin{abstract}
It was widely reported in the early 2000s that geopolymer technology exhibits superior mechanical properties and lower global warming potential (GWP) over the use of ordinary Portland cement (OPC). However, a major limitation observed in the sustainability evaluation is a lack of consideration of environmental impacts from the use of industrial waste. This observation led to the purpose of this study, which is to identify the key factors throughout geopolymer production that contribute to its sustainability performance. In this paper, two geopolymers made of fly ash (G-FA) and cenospheres (G-C) were examined by mechanical testing while their sustainability impacts on a cradle-to-grave approach were investigated. The industrial waste and transport modelling impacts were given special attention in the performed life-cycle assessment. After 28 days of curing, G-FA exhibited $64.56 \mathrm{MPa}$ and $6.03 \mathrm{MPa}$ of compressive strength and flexural strength, respectively. G-C, with $\frac{3}{4}$ of G-FA bulk density, achieved 19.09 $\mathrm{MPa}$ and $3.13 \mathrm{MPa}$, respectively, with no significant changes observed after 14 days of curing. By upscaling the inventories to $1 \mathrm{~m}^{3}$ of industrial production scale, geopolymers showed a GWP reduction up to $49.7 \%$ compared to OPC with natural aggregates and presented benefits on human health damage category by $23.7 \%$ (G-FA) to $41.6 \%$ (G-C). In conclusion, geopolymer mortars establish compressive strength and flexural strength that are adequate for construction applications and present sustainability benefits in GWP, which suggests them to be potential substitutions for OPC. However, the industrial waste treatment (i.e., preparation of fly ash) will deplete water bodies, and the sodium silicate induces significant environmental burdens during its manufacture, becoming the key factor to enhance the geopolymer's sustainability.
\end{abstract}

Keywords: sustainable construction materials; alkali-activated geopolymers; ordinary Portland cement (OPC); mechanical properties; LCA analysis; cradle-to-grave approach; endpoint/midpoint assessment; industrial waste; environmental performance; SimaPro software

\section{Introduction}

For decades, concrete has been used in the construction industry due to its cost efficiency and availability. Ordinary Portland cement (OPC), as the most common cement used in concrete, possesses several advantageous properties such as high performance in thermal conductivity and mechanical strength. On the downside, it exhibits a huge burden on the environment due to large $\mathrm{CO}_{2}$ emissions during its production [1]. The production process involves calcination, where limestone is heated at $1500{ }^{\circ} \mathrm{C}$, breaking down into calcium oxide and $\mathrm{CO}_{2}$ [2]. As reported, $50 \%$ of the total $\mathrm{CO}_{2}$ emission from cement production is generated from the calcination, while the indirect emissions are caused by the fuel combustion used to heat the kiln. As such, OPC production was claimed to be a major source of greenhouse gas (GHG) emissions worldwide as cement production was found to account for $5-7 \%$ of global $\mathrm{CO}_{2}$ emissions $[1,2]$. This has raised global awareness 
of the need to invent different sustainable cementitious material options to mitigate the huge environmental burdens from the construction industry [3].

In recent years, an alkali-activated binder, known as geopolymer cement, appears to be a solution to replace conventional concrete. The term 'geopolymer' was firstly introduced by Davidovits in the late 1970s [4] to describe a type of mineral binders that are produced by a process namely, geopolymerisation. It is a synthesis reaction between the aluminosilicate mineral (precursors) and alkali polysilicates (activator) to form an Al-O-Si bond [5]. Amongst the reported approaches to induce geopolymerisation, alkaline activation is widely known as an effective approach to form Si- and Al- precursors [6]. In geopolymer concrete (GPC) production, the cement is partially or entirely substituted with materials with high $\mathrm{SiO}_{2}$ and $\mathrm{Al}_{2} \mathrm{O}_{3}$ contents (e.g., pozzolanic material) and is activated by an alkali solution [4]. In fact, industrial waste such as fly ash (FA) and ground granulated blast furnace slag (GGBFS), as well as other naturally occurring materials such as thermally activated clay or pozzolan, can serve this purpose [5], while sodium or potassium hydroxide and silicate are the most commonly used alkali activators in current technology [6].

The technical advantages of geopolymers over traditional cement materials have been widely reported-such as their mechanical performance [7,8] and chemical resistance [9]. Most of the geopolymer studies revealed their advantageous properties such as high initial strength [7], superior fire resistance [10,11], acid resistance [5,12], and shorter setting time $[7,12]$. GPC showed 1.5 times the compressive strength of OPC, and it exhibited high early strength that can prevent breakage during transportation [7]. As revealed in previous studies, the presence of calcium in fly ash-based geopolymer is the reason for its flash setting properties $[7,8]$. These results suggest a functional use of geopolymers in precast industries [7] and prevent aluminosilicate waste materials from being disposed of in a landfill [10].

The underlying concept of geopolymer technology [13] applied to the construction industry is the improvement of sustainability. Considering the fact that geopolymer production does not involve the clinker calcination process and kiln heating process, its production is rendered to be green. Moreover, geopolymer technology has allowed the valorisation and beneficiation of industrial waste such as fly ash and granulated blast furnace slag [14]. For this reason, the environmental evaluation of geopolymers has taken off in the past several decades [15-17]. Amongst sustainability evaluations, life-cycle assessment (LCA) is commonly adopted to systematically evaluate the environmental burdens associated with the feedstock extraction for the production and the disposal of geopolymer product during its lifetime $[10,12,15,18-20]$. Due to its high mechanical strength [21,22], geopolymer had been widely investigated in order to curb the consumption of Portland cement [23]. It was identified that the GPC production entails an environmental advantage over OPC and that a reduction of GHG emissions from $42 \%$ to $64 \%$ can be achieved in the absence of clinker production $[10,15,17]$. Knowing that the LCA results are not straightforwardly comparable [15], the environmental viability of geopolymer was highlighted with regard to the global warming burdens.

On the other hand, the sustainability of geopolymer was challenged by several recent studies claiming that geopolymer materials has presented worse impacts in certain environmental damage categories due to the Chlor-alkali process, which is not required in OPC production. For instance, Dontriros et al. [19] had recognised that a brick made of geopolymer induces higher burdens to ozone depletion, human toxicity, terrestrial ecotoxicity, and fossil depletion. This finding is consistent with the study by Salas et al. [15] and Bajpai et al. [24], suggesting that GPC production is undesirable to human health. The use of alkali activators [15,16,25-27] and the electricity used during its production [26] turned out to be the main environmental burdens within the geopolymer life cycle. As suggested by Gomes et al. [28], the electrolysis of alkali activators is an energy-intensive process responsible for $36 \%$ to $58 \%$ of the impacts of GPC production. In the light of enhancing the sustainability performance of geopolymer, several authors had recommended reducing the demand for alkali activators during production $[12,24,29,30]$. Other studies demonstrated 
the possibility of fabricating the geopolymer using ambient temperature curing with the use of alkaline activators of lower alkalinity [31,32]. It was observed that changing the curing energy and alkali activator type can reduce the GHG emissions of geopolymer by $30 \%$ [33].

A review by Salas et al. [34] revealed that most of the LCA studies concerning cement and concrete did not intentionally include any impact allocations of the use of byproducts. The latest revision of the EU regulation also defined industrial waste to be a source of pollution if it is economically profitable [35]. This new definition suggested a different perspective by which to consider the environmental impacts of byproducts [18] and the necessity for a reasonable allocation method to present the long-term sustainability damages of a material.

Besides this, the logistics of geopolymers were found to be debatable because it is not an established product and its transport is not ready to be scaled-up for a comparable assessment of its sustainability [36]. Due to the inclusion of various life-cycle phases, the results of LCA may vary extensively due to a more accurate analysis concerning the transport of the raw materials and their disposal. It has been claimed that the change of transportation modes can attain a $25 \%$ reduction of GHG emissions for the GPC [33]. These findings argued that the geopolymer materials may have an unfavourable performance in sustainability, depending on the type of transportation mode-which is contrary to the intrinsic assumption that geopolymer materials always deals less environmental damage than OPC [33].

These findings raised the question that the results of the previous assessment may not substantially reveal the environmental burdens of geopolymer products, as they had limited consideration of the extraction and transportation of the byproducts. Whilst it is recognised that choices in methodological LCA may influence geopolymer's sustainability performance significantly [27,31], an environmental evaluation of the latest geopolymer concrete production with special attention given to the treatment of byproducts and transportation is needed to present the key factors that contribute to the sustainability of geopolymers in the building sector.

Hence, the aim of this study was to evaluate the mechanical properties of two geopolymers made of fly ash, cenospheres, GGBFS, and activated by sodium silicate $\left(\mathrm{Na}_{2} \mathrm{SiO}_{3}\right)$, and examine their environmental performance by scaling up the life-cycle inventory (LCI) developed at laboratory scale to industrial scale. The significance is to reveal the most critical factors needed to develop a sustainable solution for geopolymers in the future. In summary, this study suggests that geopolymer entails advantages over OPC on GWP, but it exhibits significant damages to the environment, especially regarding water consumption and contamination. From the findings, the alkali activator and the fly ash as byproducts were observed to be major parameters that should be given special attention to further enhance the sustainability of the geopolymer mix.

\section{Materials and Methods}

\subsection{Materials}

Similar to the recent study of Wong et al. [37], the raw materials fly ash (Class F) and GGBFS were sourced from the Australian Eraring Power Station (NSW) and Ecocem (Warrawong, NSW) [38], respectively. Cenospheres were sourced from Envirospheres (Australia) -ES series and ESG grade (130 $\mu \mathrm{m}$ average diameter of hollow spheres) [39]. Sodium metasilicate pentahydrate $\left(\mathrm{SiO}_{2} / \mathrm{Na}_{2} \mathrm{O}\right)$ pellets with a silica modulus of 1 were provided by Jasol's distributor, COS (Lidcombe, NSW) and the sand was supplied by Brickworks Pty. Ltd. (Wetherill Park, NSW). Table 1 reports the chemical composition of fly ash, cenospheres, and GGBFS, respectively, measured by X-ray fluorescence (XRF) in terms of oxides. It can be observed that there is a significant variation in chemical composition between the two byproducts of coal combustion thermal power plants (i.e. fly ash and cenospheres). Class F fly ash presents a low content of calcium oxide $(<15 \% \mathrm{CaO})$ and high content of silica $\left(\mathrm{SiO}_{2}\right)$, followed by alumina $\left(\mathrm{Al}_{2} \mathrm{O}_{3}\right)$, and hematite $\left(\mathrm{Fe}_{2} \mathrm{O}_{3}\right)$. Cenospheres 
consist predominantly of silica and alumina, followed by hematite and potassium oxide $\left(\mathrm{K}_{2} \mathrm{O}\right)$, which have comparable weight percent. This chemical composition is consistent with the results of previous studies on cenospheres [40]. GGBFS, as a byproduct of iron production, presents a high content of $\mathrm{CaO}$ and $\mathrm{SiO}_{2}$, followed by $\mathrm{Al}_{2} \mathrm{O}_{3}$ and $\mathrm{MgO}$. The volume density against particle size distribution of the industrial byproduct materials has been reported in Figure S1 of the Supplementary Materials. The scanning electron microscopy (SEM) images of the pure hollow cenospheres used in this study are shown in Figure S2.

Table 1. Chemical composition of fly ash [37], cenospheres, and GGBFS [37].

\begin{tabular}{|c|c|c|c|c|c|c|c|c|c|c|c|c|c|}
\hline & \multicolumn{13}{|c|}{ Elemental Oxide in wt $\%$} \\
\hline & $\mathrm{SiO}_{2}$ & $\mathrm{Al}_{2} \mathrm{O}_{3}$ & ${ }_{3} \mathrm{Fe}_{2} \mathrm{O}_{3}$ & $\mathrm{~K}_{2} \mathrm{O}$ & $\mathrm{CaO}$ & $\mathrm{TiO}_{2}$ & $\mathrm{Na}_{2} \mathrm{O}$ & $\mathrm{MgO}$ & $\mathrm{P}_{2} \mathrm{O}_{5}$ & $\mathrm{SO}_{3}$ & $\mathrm{BaO}$ & $\mathrm{Mn}_{3}$ & L.O.I \\
\hline Fly ash & 69.80 & 19.78 & 2.68 & 1.54 & 1.44 & 0.79 & 0.55 & 0.47 & 0.20 & - & - & - & 2.32 \\
\hline Ceno & 61.80 & 30.30 & 2.16 & 2.15 & 0.48 & 1.00 & 0.35 & 0.87 & 0.07 & 0.04 & 0.03 & - & 0.32 \\
\hline \multicolumn{14}{|c|}{ Wt. gain } \\
\hline GGBFS & 35.28 & 14.69 & 0.50 & 0.28 & 41.49 & 1.25 & 0.24 & 5.76 & - & 1.01 & 0.10 & 0.42 & 0.12 \\
\hline
\end{tabular}

\subsubsection{Mixture Proportion}

Table 2 presents the base composition of the two geopolymers (G-FA and G-C) investigated in this study. The mix design procedure followed the established methods for low-calcium alkali-activated FA-based concretes [41]. The blast furnace slag was either mixed with fly ash (FA) or cenospheres (C) to form the binder. For each mixture component, the weight percentage is provided as compared to one portion of the binder.

Table 2. Mix design—component-to-binder ratio by weight $\%$.

\begin{tabular}{ccccccc}
\hline & Fly Ash & Cenospheres & GGBFS & $\mathrm{Na}_{2} \mathrm{SiO}_{3}$ & Sand & Water \\
\hline G-FA & 0.4 & - & 0.6 & 0.24 & 2 & 0.505 \\
G-C & - & 0.4 & 0.6 & 0.24 & 2 & 0.505 \\
\hline
\end{tabular}

\subsubsection{Specimen Preparation}

In the preparation stage, the raw materials (e.g., binders and activator) were measured and mixed as prescribed in Table 2. The right proportion of deionised water was then added, and the resulting mixture was stirred for $2 \mathrm{~min}$ to dissolve the powder activator. After that, fine sand was also added and mixed until an even consistency was observed.

The wet mortar was filled into moulds with cavities of specific dimensions (e.g., $25 \times 25 \times 120 \mathrm{~mm}$ for mechanical tests). Lubricant (kerosene) was applied to the mould and a Dynapac BP48 vibrating table was used for $2 \mathrm{~min}$ to remove potential trapped air bubbles. After that, each mould with the wet mortar was kept in a sealable plastic container for one day at the ambient temperature of $23^{\circ} \mathrm{C}$. Lastly, the formed samples were removed and left to cure at controlled ambient laboratory temperature (i.e., $23{ }^{\circ} \mathrm{C}$ with $45 \% \pm 5 \%$ of relative humidity) within a sealed container. Before each test, the samples were polished with up to 800 nos. grit sandpaper to create an even load distribution during mechanical tests.

Figure 1 illustrates the main phases of the sample fabrication process.

The samples were cast in bars of dimension $25 \times 25 \times 120 \mathrm{~mm}$ ( 4 bars for each mould) to be tested for flexural and compressive strength. After flexural testing, $25 \mathrm{~mm}$ were cut off from both ends of the tested samples to make them ready for the compression test, ensuring that lateral cracks at the sample end did not interfere with the following compression test results. 

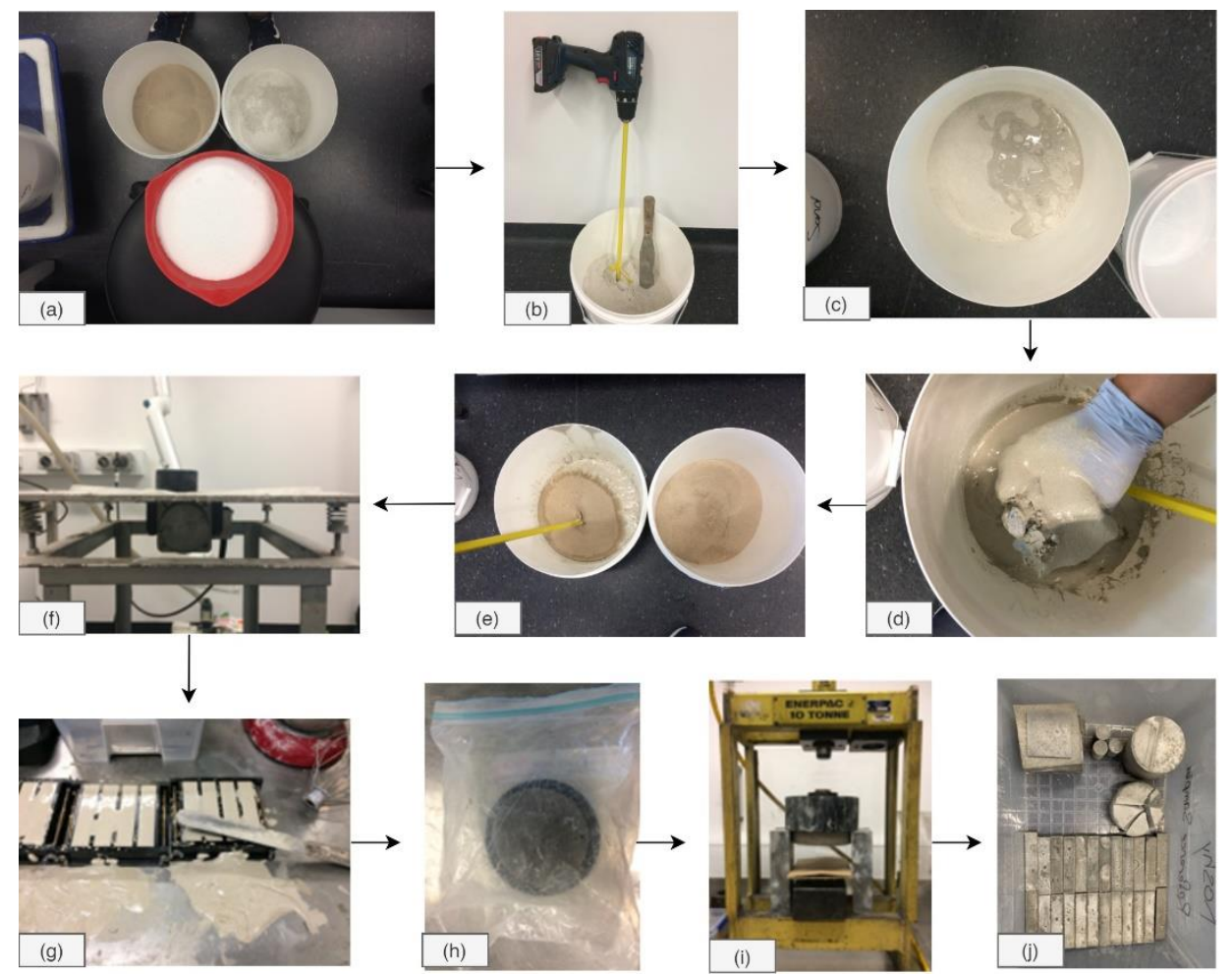

Figure 1. Sample fabrication procedure: (a) weigh raw materials, (b) mix binder and solid activator until homogenous, (c) add water, (d) dislodge unmixed clumps from bottom edges of the container, (e) add sand and mix until homogenous, (f) vibrate, (g) pour mortar into moulds and level with a spatula, (h) seal for $24 \mathrm{~h}$, (i) extraction of the formed samples from the moulds, then (j) store them in a sealed container.

\subsubsection{Flexural and Compression Testing}

An Instron 5982 high-capacity universal testing machine was used to test the flexural and compressive strength of the samples countering a $100 \mathrm{kN}$ load cell. The testing intervals were at $7,14,28,56$, and 91 days and the average compressive and flexural results were recorded for each curing time.

The dimensions of the specimens were measured with a Vernier calliper before proceeding with the flexural and compression testing at $773 \mathrm{~N} / \mathrm{s}$ and $1200 \mathrm{~N} / \mathrm{s}$ loading rates, respectively, in accordance with ASTM C348 [42] and ASTM C109 [43]. A deviation from ASTM C348 and ASTM C109 occurred on the type and dimension of the samples used for the flexural and compression tests, respectively. In accordance with Wong et al. [37], the standard dimensions of the samples for the flexural test were modified to $25 \times 25 \times 120 \mathrm{~mm}$ to cut the ends of the bars and make cubes $(25 \times 25 \times 25 \mathrm{~mm})$ that did not exceed the loading capacity of the machine for the compression tests (maximal load of $100 \mathrm{kN}$ ). The standard flexural strength loading rate $P$, corresponding to $2640 \mathrm{~N} / \mathrm{mm}$, was adjusted to suit the smaller sized sample according to the following Equation (1):

$$
\sigma_{b}=\frac{3}{2} * \frac{P * L}{b * d^{2}}
$$

where $\sigma_{b}$ is the maximum flexural stress, $L$ is the distance between the loading bearing points, and $b$ equal to $d$ is the width of the sample.

The results of the mechanical tests obtained for the two geopolymers remain comparable even if the sample dimension is scaled [44]. 


\subsection{Life-Cycle Assessment (LCA) Methodology}

LCA in accordance with ISO 14040 [45] and ISO 14044 [46] was conducted to examine the environmental impacts throughout the geopolymer life cycle from raw material acquisition to end-of-life (EoL) treatment. The four main phases in the LCA are (1) goal and scope, (2) inventory analysis, (3) impact assessment, and (4) interpretation [47]. Calculations were performed using the SimaPro 9.1.1 software [48].

\subsubsection{Goal and Scope}

The goal of this assessment was to determine the environmental performance of two types of geopolymers (e.g., G-FA and G-C) and benchmark their environmental burdens with OPC made of natural (NAC) or recycled aggregates (RAC). In this comparison, equal volume is a practical parameter that can be controlled across all material types with the mix design of all the ingredients strictly remaining within the volume. Given that the geopolymers are emerging materials that can be considered a greener replacement for OPC, compressive strength was considered as a comparable factor with OPC due to their potential applications in constructions. As the compressive strength developing times for all material types are different [49], geopolymers and concretes that achieve the range between standard compressive strength $(20 \mathrm{MPa})$ and high compressive strength $(65 \mathrm{MPa})$ after 28 days of curing were selected. Therefore, a functional unit (FU) of one cubic meter of material with compressive strength ranging from $20 \mathrm{MPa}$ to $65 \mathrm{MPa}$ after curing for 28 days was assessed in this study.

As demonstrated in previous studies, the geopolymer mortars have the potential to be used for different construction applications and exhibit distinctly higher or comparable mechanical strength than conventional OPC mortars. In this study, OPC concretes from literature (i.e. NAC and RAC) were selected to compare their LCA results with the relevant one of the two presented geopolymer mortars (i.e. G-FA and G-C) as they share the same construction applications based on their compressive strength. This has been done in order not to restrain the LCA comparison to similar materials.

In this paper, a comparative 'cradle to grave' (end-of-life scenario) approach in accordance with EN 15804 [50] was adopted. Given that there was no single agreed LCA framework established in Australia, the European Union's EN 15804 standard was favoured, not only as it applies the ISO principles throughout its standards, but it inclusively addresses the issues of operational energy and disposal [51], in which the energy-intensive materials would be specified through the assessment.

The system boundaries in this LCA for geopolymers and OPC are illustrated in Figures 2 and 3, respectively. The studied system comprises four phases from raw materials production (cradle), construction process, and the use-phase-to-disposal-phase (grave) of materials. Four material types were studied: (i) geopolymer with fly ash as the binder (G-FA), (ii) geopolymer with cenospheres as the binder (G-C); (iii) concrete made of natural aggregates (NAC), and (iv) concrete made of recycled aggregates (RAC).

In the product stage, the extraction of raw materials, including the crystallisation of sodium silicate, treatment of FA and GGBFS, cement production, and extraction of sand, natural aggregate, and recycled aggregate, were calculated.

In the construction process stage, transportation of all materials to the mixing plant was firstly considered, and the construction of all concretes followed the typical processes of OPC concrete construction, including the production of mortar, transportation to the construction site, and setting of concrete with concrete pump and vibrator. All concretes were assumed to be cured at ambient temperature, hence no energy was involved in the curing process.

In general, the durability performance of geopolymer is superior to that of OPC concrete within the range of the considered exposure [52]. In this study, it was assumed that there is no need for any maintenance or operational energy once the material is constructed and the durability of all materials was assumed the same. Therefore, no impact was considered in the use stage. 


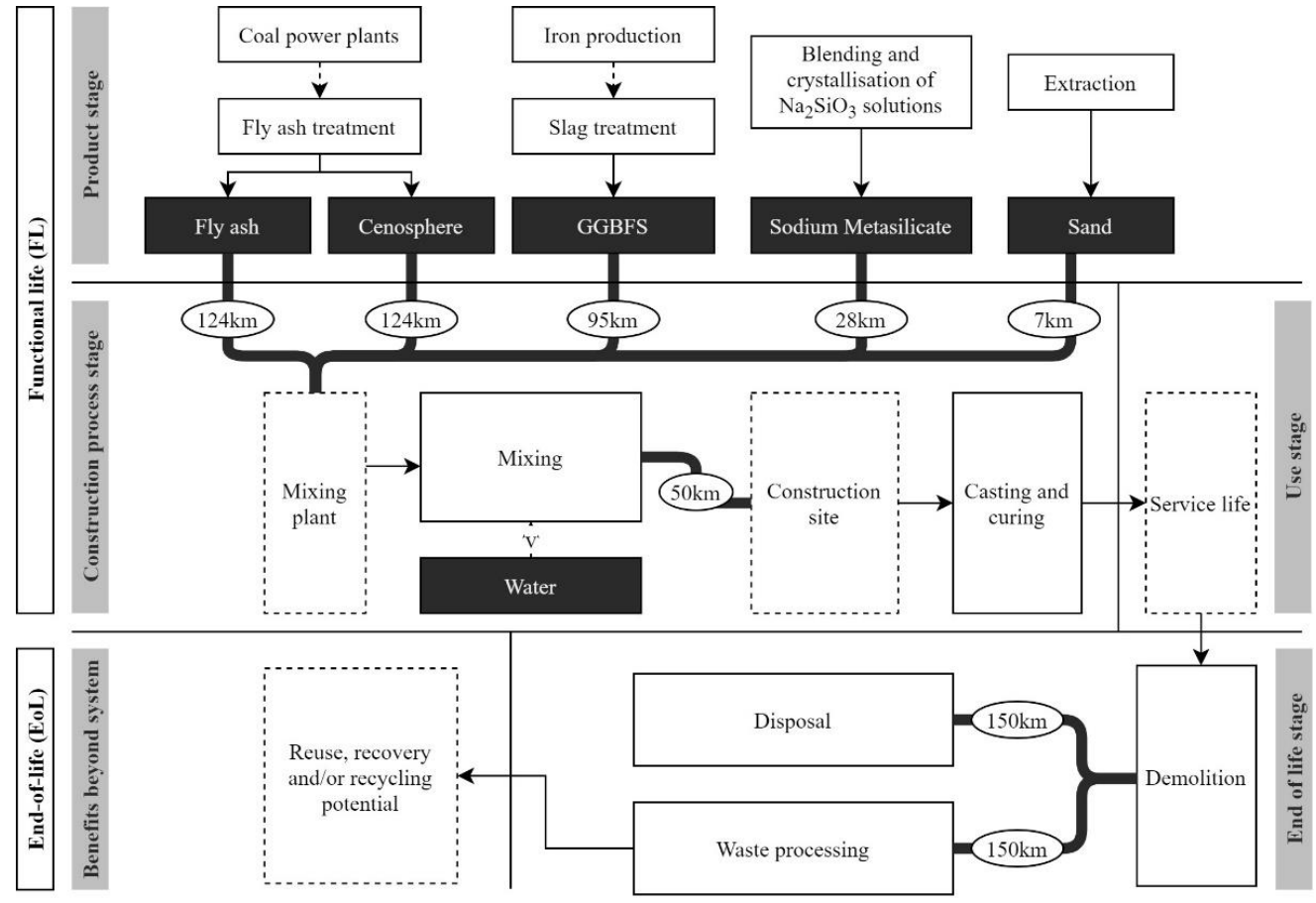

$\square$ Process in the system

:-... Process out of the system

$\bigcirc$ Transport distance

$\rightarrow$ Allocation procedure

Figure 2. System boundaries of G-FA and G-C.

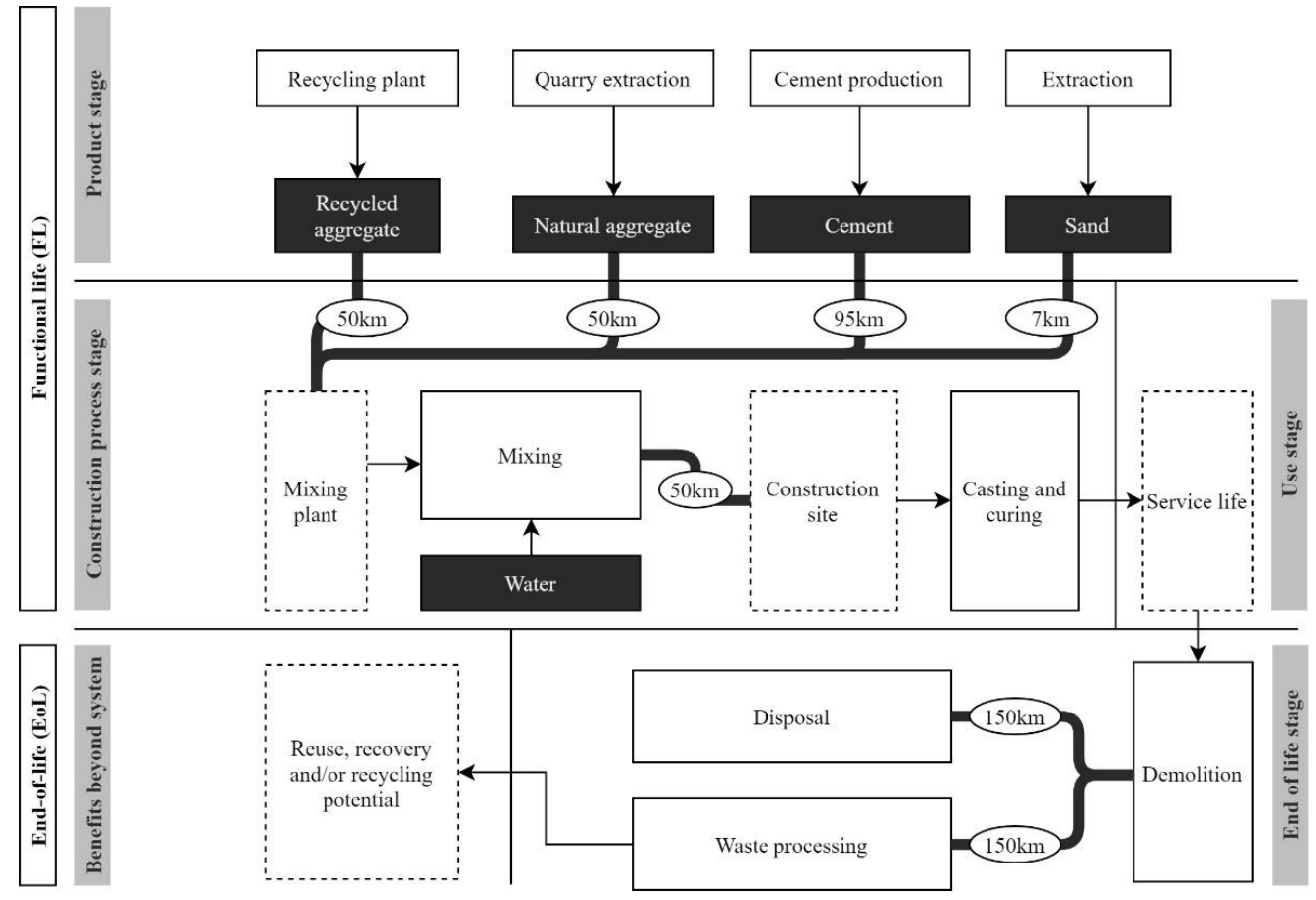

Raw materials

$\square$ Process in the system

$\bigcirc$ Transport distance

Process out of the system

$\rightarrow$ Allocation procedure

Figure 3. System boundaries of NAC and RAC. 
Eventually, all concrete types were demolished at the end-of-life stage and sent to the recycling plant, while those non-recyclable parts would be sent to disposal in a landfill.

\subsubsection{Inventory Analysis (LCI)}

The mix design of the four material types at 1 cubic meter is summarised in Table 3. The proportions of the geopolymer mortars were developed at laboratory scale from previous tests as detailed in Table 2 and a scale-up to industrial-scale was conducted based on the developed density. The amounts of the component materials of two OPC concretes were developed by Etxeberria et al. [49] using Type I Portland cement to achieve compressive strength at a minimum of $30 \mathrm{MPa}$ at 28 days of curing.

Table 3. Amounts of materials per FU (i.e., $1 \mathrm{~m}^{3}$ ), compressive strength, and density of geopolymers and OPC concretes.

\begin{tabular}{ccccc}
\hline & G-FA & G-C & NAC & RAC \\
\hline Fly ash $(\mathrm{kg})$ & 224 & - & - & - \\
Cenospheres $(\mathrm{kg})$ & - & 167 & - & - \\
GGBFS $(\mathrm{kg})$ & 336 & 250 & - & - \\
Natural aggregate $(\mathrm{kg})$ & - & - & 1207 & - \\
Recycled aggregate $(\mathrm{kg})$ & - & - & - & 1123 \\
Sodium silicate $(\mathrm{kg})$ & 134 & 100 & - & - \\
Cement $(\mathrm{kg})$ & - & - & 300 & 325 \\
Sand $(\mathrm{kg})$ & $1.12 \mathrm{E} 3$ & 834 & 765 & 683 \\
Water $(\mathrm{kg})$ & 283 & 211 & 165 & 162 \\
\hline Compressive strength $(\mathrm{MPa})$ & $64.6 \mathrm{MPa}$ & $20.0 \mathrm{MPa}$ & $35.5 \mathrm{MPa}$ & $38.3 \mathrm{MPa}$ \\
Density $\left(\mathrm{kg} / \mathrm{m}^{3}\right)$ & 2095.75 & 1562.01 & 2442.00 & 2301.00 \\
\hline
\end{tabular}

In the product stage, the inventories of FA and GGBFS were allocated from the impacts of their primary processes (such as coal power plants and iron production) using the reported economic allocation coefficients [35], Ce, followed by the impacts for the secondary processes (such as slag and fly ash treatment). The allocation percentages for impacts from coal power plants and iron production were $1.27 \%$ and $0.21 \%$, respectively, based on the Australian market suggested by Shobeiri et al. [33].

The treatment plant to produce the cenospheres had not been considered because the conventional production of cenospheres that involves the separation from coal fly ash had been reported as an inefficient method [53] due to the very limited volume of cenospheres in fly ash [54]. An allocation of $1.5 \%$ of the impacts to the cenospheres from the production of fly ash was assumed in this analysis.

Inventory values for the cement, natural aggregate, and recycled aggregate used in this study were developed by Marinković et al. [55]. The inventories of other materials were collected from the Ecoinvent 3.7.1 database [56] as listed in Table 4.

Table 4. Inventories from Ecoinvent 3.7.1.

\begin{tabular}{cc}
\hline & Ecoinvent 3.7.1 Database \\
\hline $\mathrm{Na}_{2} \mathrm{SiO}_{3}$ & Sodium silicate, without water, in 37\% solution state (RoW) market for sodium silicate \\
$\mathrm{Sand}$ & Sand (RoW) market for sand \\
Water & Water, deionised (RoW) market for water \\
\hline
\end{tabular}

In the construction process stage, the inventories for the mixing plant, concrete pump, and vibrator were obtained from Kawai et al. [57]. The concrete plant was chosen for concrete mixing in this system. A concrete pump at a rate of $95-110 \mathrm{~m}^{3} / \mathrm{h}$ and flexible shaft vibrator were used for concrete placing and compaction, respectively.

At the end-of-life stage, the impacts associated with the demolition were obtained from the study of Kawai et al. [57]. As suggested by Zhu et al. [58], the new geopolymer concrete 
made of less than $80 \%$ of recycled geopolymer fine aggregates achieved a decline rate of less than $20 \%$ for their compressive strength. Thus, the recycling rate of geopolymers in this study was set to $80 \%$, which means that $80 \%$ of the crushed geopolymer obtained after the demolition process would be transported to the recycling plant while $20 \%$ of non-recyclable components would be disposed of at a landfill. In the recycling plant, the geopolymer is crushed to the required particle size for reuse [58]. However, the impacts of waste treatment were not included in this study as they are beyond the defined system boundary.

Regarding the transportation, the main case scenario illustrated the minimum distance of batching plants and material sources located in Sydney, Australia [33]. The transportation of cenospheres was assumed to be of equal distance as the FA since the cenospheres were extracted from the same flow of coal power plants as the FA [40]. Backhaul (or the return trip) was considered for each process to address the energy consumption used to return the vehicles to their departure site. A backhaul factor of $60 \%$ of the energy use and emissions of the fronthaul was assumed in this study [59].

To investigate the impacts caused by transportation throughout the life cycle, two additional transport scenarios (S1 and S2) for the geopolymers were created for sensitivity analysis. G-FA was selected as the research subject due to its comprehensive compositions. S1 was to test the impacts of the raw material transportation; the transportation of raw materials to the mixing plant was doubled; while the transportation to the construction and disposal sites remained unchanged. In S2, merely the distances to the construction site and disposal sites were upscaled to two times their initial distances, while the rest remained unchanged to test the efficiency of recycling the geopolymers. The scenarios are listed in Table 5. Inventories for energy/fuel and transport are reported in Tables S1 and S2 of the Supplementary Materials.

Table 5. Transport scenarios.

\begin{tabular}{cccc}
\hline & \multicolumn{3}{c}{ Transport Distance (km) } \\
\cline { 2 - 4 } & Main Case & S1 & S2 \\
\hline FA & 124 & 248 & 124 \\
GGBFS & 95 & 190 & 95 \\
Cenospheres & 124 & - & - \\
$\mathrm{Na}_{2} \mathrm{SiO}_{3}$ & 28 & 56 & 28 \\
Sand & 7 & 14 & - \\
Aggregates & 50 & - & - \\
(Natural/recycled) & 95 & - & 100 \\
Cement & 50 & 50 & 300 \\
To construction site & 150 & 150 & 300 \\
To landfill & 150 & 150 & \\
To recycling plant & & &
\end{tabular}

\subsubsection{Impact Assessment (LCIA)}

The life-cycle impact assessment was carried out using IPCC 2013 GWP 100a v1.03 and ReCiPe 2016 v1.1 midpoint/endpoint methods, Hierarchist version. The ReCiPe endpoint indicators, which are separated into three categories, show the ecological effect on three higher aggregation levels corresponding to the impacts on human health, ecosystem, and resource scarcity [60]. Midpoint results are separated into several ecological category indicators with specific relevance, which is a more complex approach and usually focused on presenting the results for specific impacts.

An overview of the different impact categories for each method and their abbreviations are listed in Table 6. 
Table 6. Methods and impact categories.

\begin{tabular}{|c|c|c|c|}
\hline Method & Impact Category & Abbreviation & Unit \\
\hline IPCC GWP 100a & Global warming potential & GWP & $\mathrm{kgCO}_{2}$-eq \\
\hline \multirow{3}{*}{ ReCiPe endpoint } & Human health & $\mathrm{HH}$ & Year \\
\hline & Ecosystem quality & ED & Species $\times$ year \\
\hline & Resource availability & RA & Dollar \\
\hline \multirow{17}{*}{ ReCiPe midpoint } & Ozone depletion & ODP & kg CFC-11 \\
\hline & Ionising radiation & IRP & kBq CO-60 \\
\hline & Fine particulate matter formation & PMFP & kg PM2.5 \\
\hline & Oxidant formation, ecosystem & EOFP & $\mathrm{kg} \mathrm{NO}$ \\
\hline & Oxidant formation, human health & HOFP & $\operatorname{kg} \mathrm{NO}_{\mathrm{x}}$ \\
\hline & Terrestrial acidification & TAP & $\mathrm{kg} \mathrm{SO}_{2}$ \\
\hline & Freshwater eutrophication & FEP & $\mathrm{kg} \mathrm{P}$ \\
\hline & Marine eutrophication & MEP & $\mathrm{kg} \mathrm{P}$ \\
\hline & Human toxicity, cancer & HTPс & kg 1,4-DCB \\
\hline & Human toxicity, non-cancer & HTPnc & kg 1,4-DCB \\
\hline & Terrestrial ecotoxicity & TETP & kg 1,4-DCB \\
\hline & Freshwater ecotoxicity & FETP & $\operatorname{kg} 1,4-\mathrm{DCB}$ \\
\hline & Marine ecotoxicity & METP & kg 1,4-DCB \\
\hline & Land use & LOP & $\mathrm{M}^{2} \times \mathrm{yr}$ \\
\hline & Water use & WCP & $\mathrm{M}^{3}$ \\
\hline & Mineral resource scarcity & SOP & $\mathrm{kg} \mathrm{Cu}$ \\
\hline & Fossil resource scarcity & FFP & kg oil \\
\hline
\end{tabular}

\subsection{LCA Limitations}

The preliminary assumptions applied to the boundary conditions of the study, the stages, and selected impact categories may affect the LCA results, as well as the discussions and conclusions drawn from the analysis. However, all the assumptions were made in a consistent way between geopolymers and OPC to allow a comparison analysis.

The LCA analysis was limited to the impact categories associated with the selected methods (i.e., IPCC 2013 GWP 100a v1.03 and ReCiPe 2016 v1.1 midpoint/endpoint) and to the Australian context.

Furthermore, the effect of the different material durability on the environmental performance was not considered in this study, as it was assumed that there was a similar durability for the four materials.

A sensitivity analysis was performed to mitigate the uncertainty associated with the lack of real data on transport distances and to estimate their potential contribution to the overall environmental impact.

\section{Results}

This section presents the results deriving from both the geopolymer mechanical in-lab characterisation and the LCA comparison between geopolymers and OPCs.

\subsection{Mechanical Performance}

The flexural and compressive strength development of the geopolymer samples are reported in Tables 7 and 8.

Table 7. Flexural strength of geopolymer mortar compositions.

\begin{tabular}{cccccc}
\hline & \multicolumn{5}{c}{ Flexural Strength [MPa] } \\
\cline { 2 - 6 } & 7 Days & 14 Days & 28 Days & 56 Days & 91 Days \\
\hline G-FA & 4.80 & 4.90 & 6.03 & 8.10 & 8.70 \\
G-C & 2.63 & 3.13 & - & - & 3.68 \\
\hline
\end{tabular}


Table 8. Compressive strength of geopolymer mortar compositions.

\begin{tabular}{cccccc}
\hline & \multicolumn{5}{c}{ Compressive Strength [MPa] } \\
\cline { 2 - 6 } & 7 Days & 14 Days & 28 Days & 56 Days & 91 Days \\
\hline G-FA & 39.23 & 56.63 & 64.56 & 65.39 & 77.62 \\
G-C & 13.95 & 19.09 & 20.00 & - & 22.14 \\
\hline
\end{tabular}

The flexural strength and compressive strength of geopolymer mortar made of binder ratio 2/3 (FA/GGBFS) were recorded at $6.03 \mathrm{MPa}$ and $64.56 \mathrm{MPa}$, respectively, after 28 days of curing. A growing trend was observed during the flexural and compressive strength testing in which G-FA achieved on day 91 its maximum flexural and compressive strength at $8.70 \mathrm{MPa}$ and $77.62 \mathrm{MPa}$, respectively. These results are consistent with the mechanical performance reported in previous studies for geopolymers mortar having the same binder ratio [37].

As described in Table 2, a second sample batch was fabricated by entirely replacing the FA with cenospheres. The ceno-based geopolymer mortar, G-C, was measured at 3.13 MPa and 19.09 MPa, with no significant change observed after 14 days of curing. The replacement of cenospheres reduced the overall weight of the sample to $\frac{3}{4}$ of the base sample weight, and the mechanical strength of samples was directly proportional to the reduction of weight. This observation is in agreement with a recent study by Adesina, A. [61]. As shown in Tables 7 and 8, G-C presented limited growth after 14 days and a growing trend was observed during the flexural and compressive strength testing in which G-C achieved on day 91 its maximum flexural and compressive strength at $3.68 \mathrm{MPa}$ and $22.14 \mathrm{MPa}$, respectively.

\subsection{Global Warming Potential (GWP)}

Figure 4 compares the $\mathrm{CO}_{2}$ equivalent $\left(\mathrm{CO}_{2}\right.$-eq) emissions, calculated using the IPCC 2013 GWP 100a impact assessment approach, that were released from the production of $1 \mathrm{~m}^{3}$ of each material. It can be seen from Figure 4 that the $\mathrm{CO}_{2}$-eq arising from the functional life of geopolymers is lower than those arising from OPC concretes in all cases. Considering the GHG emissions associated with the RAC production as the baseline (100\%), the production of geopolymers emits $34.6 \%$ (G-FA) to $49.7 \%$ (G-C) less GHGs as compared to that of NAC. The production of OPC concrete using recycled aggregates demonstrates a slight increase when compared to NAC; the observed difference corresponds to $5.8 \%$.

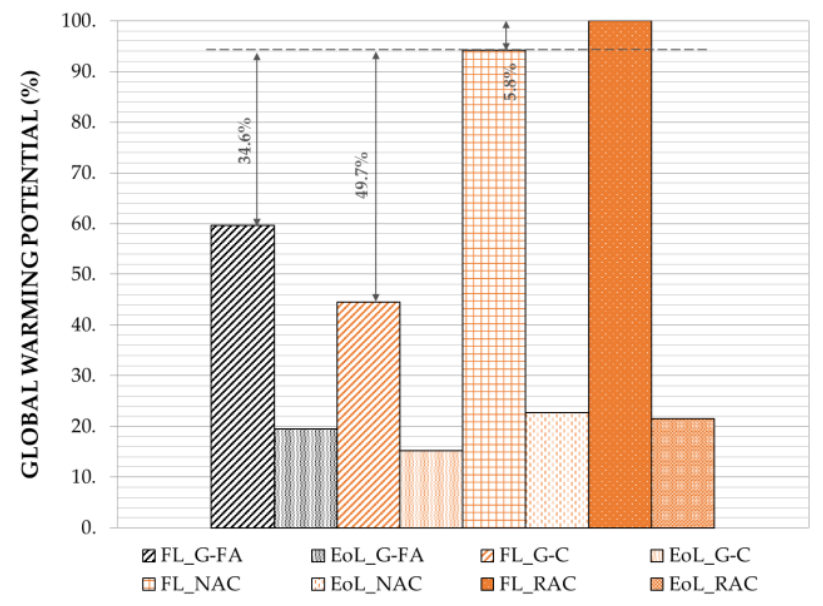

Figure 4. IPCC GWP 100a characterisation results.

The emissions arising from each process are shown in Table 9. The use of sodium silicates is shown to have the greatest GWP burden, ranging from $33.1 \%$ (G-C) to $33.4 \%$ (G-FA), while the production of FA or cenospheres present noticeable impacts ranging from 
$17.9 \%$ (G-C) to $18.16 \%$ (G-FA). Other items, such as GGBFS (less than $6.45 \%$ of $\mathrm{CO}_{2}$-eq), sand and water (less than $2.71 \%$ of $\mathrm{CO}_{2}$-eq), and batching (less than $4.21 \%$ of $\mathrm{CO}_{2}$-eq) of geopolymers have a lesser relevant impact on GWP.

Table 9. Total $\mathrm{CO}_{2}$-eq emissions for each material.

\begin{tabular}{|c|c|c|c|c|c|c|c|c|}
\hline \multirow{2}{*}{$(\mathrm{kg} \mathrm{CO}-\mathrm{eq})$} & \multicolumn{2}{|c|}{ G-FA } & \multicolumn{2}{|c|}{ G-C } & \multicolumn{2}{|c|}{ NAC } & \multicolumn{2}{|c|}{ RAC } \\
\hline & FL $^{1}$ & EoL $^{2}$ & FL & EoL & FL & EoL & FL & EoL \\
\hline Total emissions & \multicolumn{2}{|c|}{473} & \multicolumn{2}{|c|}{357} & \multicolumn{2}{|c|}{699} & \multicolumn{2}{|c|}{727} \\
\hline Emissions & 357 & 116 & 266 & 91.3 & 563 & 136 & 598 & 129 \\
\hline Sodium silicate & 158 & - & 118 & - & - & - & - & - \\
\hline FA & 85.9 & - & - & - & - & - & - & - \\
\hline Cenospheres & - & - & 64.0 & - & - & - & - & - \\
\hline GGBFS & 30.5 & - & 22.7 & - & - & - & - & - \\
\hline Cement & - & - & - & - & 468 & - & 507 & - \\
\hline Sand & 12.80 & - & 9.51 & - & 8.72 & - & 7.79 & - \\
\hline Natural aggregate & - & - & - & - & 3.33 & - & - & - \\
\hline Recycled aggregate & - & - & - & - & - & - & 3.82 & - \\
\hline Water & 0.1080 & - & 0.0806 & - & 0.0632 & - & 0.0620 & - \\
\hline Transportation & 48.71 & 86.90 & 36.28 & 64.80 & 59.86 & 101.00 & 57.16 & 95.10 \\
\hline Concrete plant & 19.9 & - & 14.8 & - & 23.2 & - & 21.8 & - \\
\hline Concrete pump & 0.704 & - & 0.704 & - & 0.704 & - & 0.704 & - \\
\hline Vibrator & 0.0017 & - & 0.0017 & - & 0.0017 & - & 0.0017 & - \\
\hline Demolition & - & 17.9 & - & 17.9 & - & 17.9 & - & 17.9 \\
\hline Waste & - & 11.55 & - & 8.61 & - & 16.76 & - & 15.81 \\
\hline
\end{tabular}

${ }^{1}$ FL refers to the functional life including raw materials production and construction process. ${ }^{2}$ EoL refers to the end-of-life phase of the product.

Regarding the OPC concretes, the cement manufacture is responsible for more than $67.0 \%$ (NAC) of the life-cycle impacts. It also explains the higher GWP of RAC (at $727 \mathrm{~kg}$ $\mathrm{CO}_{2}$-eq) than NAC (at $699 \mathrm{~kg} \mathrm{CO}$-eq), as the use of recycled aggregate imposes higher demand on the amount of cement as listed in Table 3. Besides this, it is worth noting that transportation has a significant contribution to the life-cycle impacts of all material types (between $20.94 \%$ and $28.67 \%$ ).

\subsection{Endpoint Assessment}

Figure 5 illustrates the endpoint impact of functional life (FL) and end-of-life (EoL) of the four materials in percentage. It can be seen from Figure 5 that the life-cycle processes of OPC concretes have high adverse impacts on the human health damage category $(\mathrm{HH})$. The impact of RAC is the highest, followed by NAC, G-FA, and G-C. As observed, the production of RAC utilises $8.3 \%$ more cement than NAC to bind the aggregates, generating higher impacts on the $\mathrm{HH}$ than NAC. The production of geopolymers demonstrates an observable percentage reduction on $\mathrm{HH}$ by $23.7 \%$ to $41.6 \%$ for G-FA and G-C, respectively, as compared to NAC.

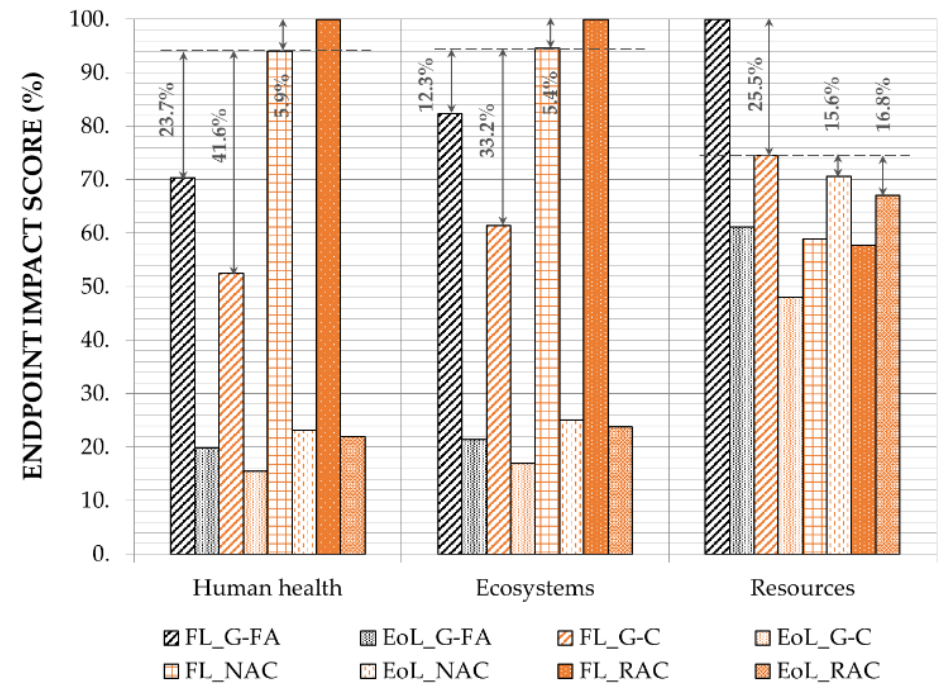

Figure 5. ReCiPe endpoint level assessment results (\%). 
Table 10 summarises the endpoint assessment results. Considering the $\mathrm{HH}$ impacts by the EoL phase, the impacts are likely determined by the density of the materials due to the proportional relationships between the weight and required energy to demolish and transport the waste. As seen in Table 10, the highest impact is shown by EoL-NAC (3.01E-4 DALY) having the highest density, followed by EoL-RAC (94.7\% as NAC), EoL-G-FA (85.4\% as NAC), then EoL-G-C (67.1\% as NAC).

Table 10. Impact scores for endpoint damage categories for each material.

\begin{tabular}{cccccccccc}
\hline \multirow{2}{*}{$\begin{array}{c}\text { Damage } \\
\text { Category }\end{array}$} & \multirow{2}{*}{ Unit } & & \multicolumn{2}{c}{ G-FA } & \multicolumn{2}{c}{ G-C } & \multicolumn{2}{c}{ NAC } & \multicolumn{2}{c}{ RAC } \\
\cline { 3 - 9 } & & FL $^{\mathbf{1}}$ & EoL $^{2}$ & FL & EoL & FL & EoL & FL & EoL \\
\hline Human health & DALY & $9.13 \mathrm{E}-4$ & $2.57 \mathrm{E}-4$ & $6.81 \mathrm{E}-4$ & $2.02 \mathrm{E}-4$ & $1.22 \mathrm{E}-3$ & $3.01 \mathrm{E}-4$ & $1.3 \mathrm{E}-3$ & $2.85 \mathrm{E}-4$ \\
Ecosystems & Species.yr & $2.37 \mathrm{E}-6$ & $6.17 \mathrm{E}-7$ & $1.77 \mathrm{E}-6$ & $4.87 \mathrm{E}-7$ & $2.72 \mathrm{E}-6$ & $7.23 \mathrm{E}-7$ & $2.88-6$ & $6.87 \mathrm{E}-7$ \\
Resources & USD2013 & 28.0 & 17.1 & 20.9 & 13.4 & 16.5 & 19.8 & 16.2 & 18.8 \\
\hline
\end{tabular}

${ }^{1}$ FL refers to the functional life, including raw materials production and construction process. ${ }^{2}$ EoL refers to the end-of-life phase of the product.

Considering the ecosystem quality damage category (EQ), OPC concretes exhibit higher negative impacts than geopolymers in both the functional life or the end-of-life phases. It can be seen in Figure 5 that the environmental impacts of FL_RAC on EQ is the highest among the four materials, which is $5.4 \%, 12.3 \%$, and $33.2 \%$ higher than FL_NAC, FL_G-FA, and FL_G-C, respectively. In contrast, geopolymers do not require cement, and have caused a lesser environmental impact in the EQ, with FL_G-C exhibiting the least impact (1.77E-6 Species.yr). Observing the EoL phase, the four materials exhibit similar impacts in the EQ, while the negative impacts are potentially affected by the waste transportation. It can be seen in Table 10 that EoL_NAC imposes the largest impact (7.23E-7 Species.yr), followed by EoL_RAC, EoL_G-FA, and EoL_G-C.

The damage to the resources damage category (RD) during the functional life of G-FA (28 USD2013) is higher than that of the two OPC concretes and G-C, which increases by $69.7 \%$ compared to NAC as presented in Table 10. The OPC concrete production presents similar damage in RD when comparing the production of NAC with that of RAC (1.2\% higher impact for NAC), and causes less damage than the geopolymers. In particular, RAC causes $22.5 \%$ less damage than G-C and $42.1 \%$ less damage than G-FA, as seen in Figure 5 . Observing the EoL phase in Table 10, the effects of disposal of the G-FA and OPC concretes are found to be approximately the same. The difference of G-C suggests that concretes with higher density consume more fuel in transportation and waste treatment. As a result, the EoL_NAC presents the highest impact on RD, followed by EoL_RAC (94.9\%), EoL_G-FA (89.4\%), and EoL_G-C (67.7\%) as compared to the production of EoL_NAC.

Figure 6 illustrates the endpoint impact scores of the FL and EoL of the materials. The figure shows that the two geopolymers exhibit a lower total negative effect on the environment than OPC concretes. The functional life of RAC has the highest total impact score (18.2 pt), followed by NAC (17.1 pt), G-FA (13.2 pt), and G-C (9.8 pt). The result suggests that the EoL of the geopolymers does not own significant advantage over the OPC concretes on the environmental issues as the impact score of geopolymers' end-of-life is between $2.96 \mathrm{pt}$ (EoL_G-C) to $3.77 \mathrm{pt}$ (EoL_G-FA), while the OPC concretes score about $4.19 \mathrm{pt}$ (EoL_RAC) to $4.41 \mathrm{pt}$ (EoL_NAC). Observing Figure 6, it can be seen that the human health damage category is the most-affected category by the life cycle of all material types.

In order to identify the contributing factors in the functional life of the different materials, the processes from the production stage to the construction stage of four materials were evaluated. Figures 7-10 present the endpoint scores for G-FA, G-C, NAC, and RAC, respectively, including raw materials, transportation, and the batching process.

Figure 7 suggests that the majority of the negative impacts from G-FA are caused by the alkaline activator (sodium silicate) and mostly on $\mathrm{HH}$. The total endpoint score for $\mathrm{Na}_{2} \mathrm{SiO}_{3}$ is $6.0 \mathrm{pt}$, which contributes $45.6 \%$ of the impacts on the functional life of the G-FA mix. 


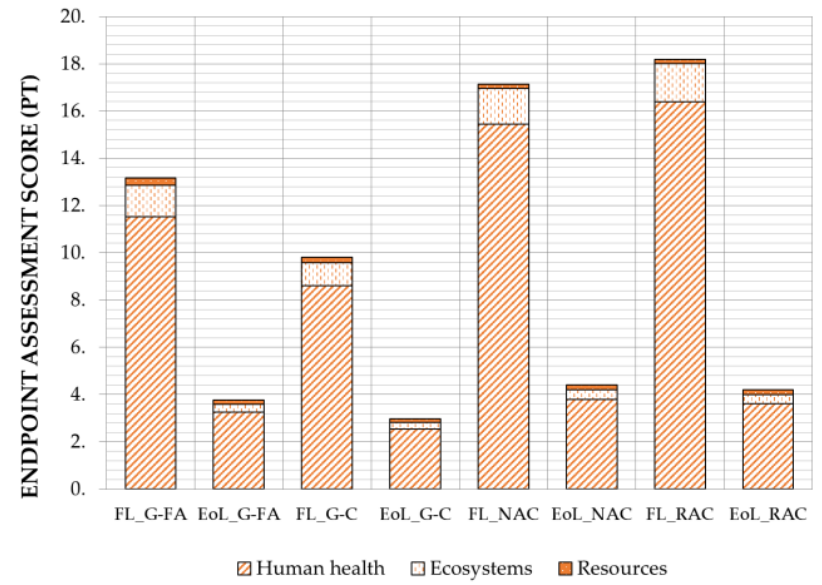

Figure 6. Endpoint score of different phases for each material.

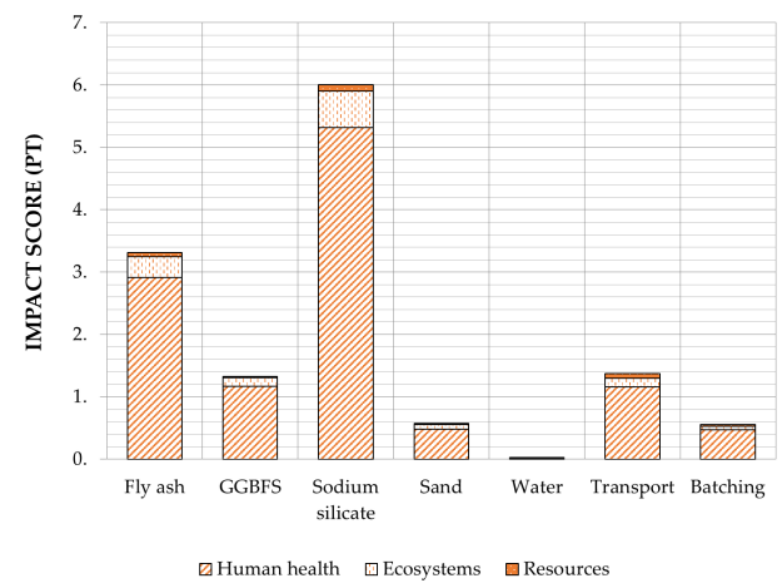

Figure 7. Endpoint score of the G-FA functional life.

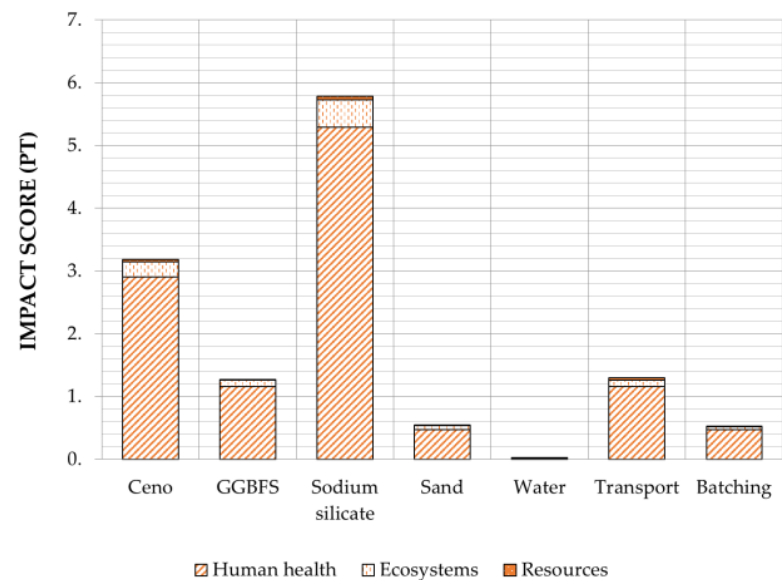

Figure 8. Endpoint score of the G-C functional life.

A similar result is observed for G-C as demonstrated in Figure 8, and the sodium silicate contributes $20.6 \%$ more impacts to the G-C mix (5.78 pt) than to the cenospheres (3.18 pt) — the second highest contributor. Besides this, high environmental loads (25.2\%) were observed from both the FA and cenospheres extractions in the functional lives of G-FA and G-C. 


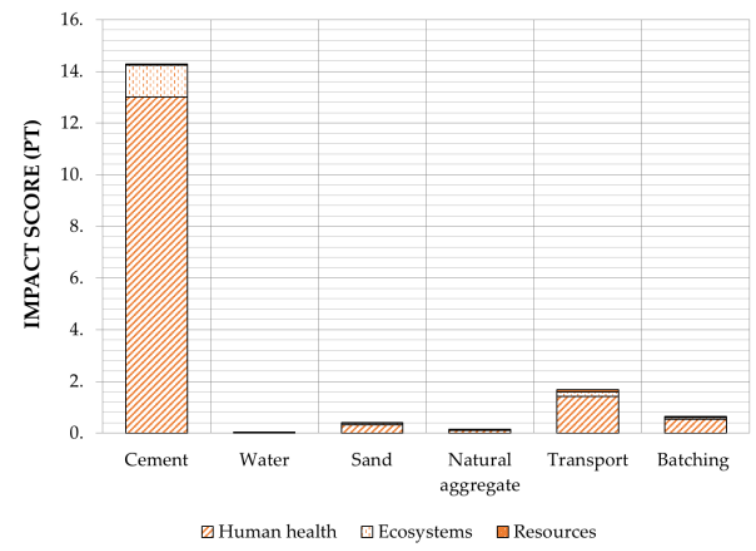

Figure 9. Endpoint score of the NAC functional life.

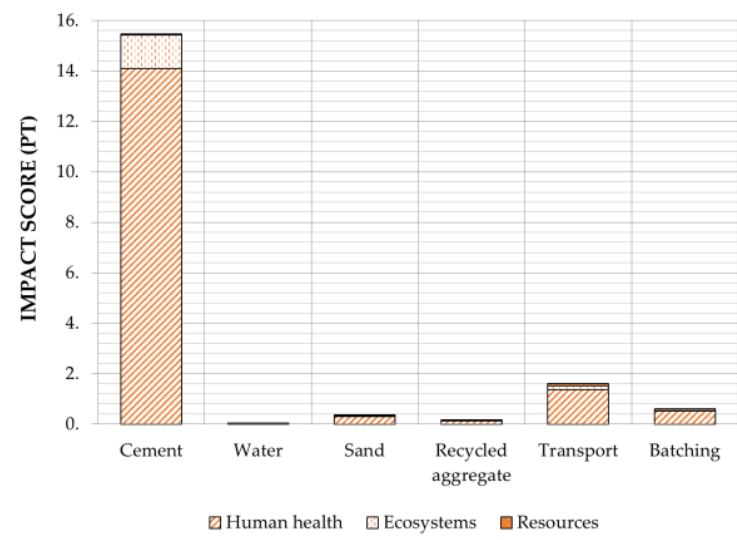

Figure 10. Endpoint score of the RAC functional life.

Considering the OPC concretes, cement production presents the highest negative impact on the environment. $\mathrm{HH}$ is mostly impacted, and cement is responsible for $83.4 \%$ and $85.1 \%$ of the environmental impacts of NAC (14.28 pt) and RAC (15.47 pt), respectively.

\subsection{Midpoint Assessment}

Assessment at the midpoint level is able to reveal the impact of materials and processes on different damage categories with more certainty [60]. Figure 11 presents the comparison of the midpoint level life-cycle impacts of the four investigated materials. It can be seen in Figure 11 that OPC concretes deal with significant impacts to PMFP and HOFP categories than geopolymer mortars. A similar trend can be seen in GWP, EOFP, and TAP, where geopolymers are observed to have sustainability advantages over OPC.

While assessing the GWP from the midpoint level, it can be observed that the results are congruent with the outcomes of the IPCC approach, where RAC has the highest impact on GWP, followed by NAC, G-FA, and G-C. However, G-FA shows the highest impacts among the four materials in several other categories. For instance, NAC and RAC present advantages in IRP and ODP. In particular, NAC presents $21.64 \%$ and $3.60 \%$ less impacts than G-FA, respectively under IRP and ODP. Similar trends are observed in TETP and FFP; $\mathrm{G}-\mathrm{C}$, with the smallest density, has the least impact among all materials in these categories. In both HTPc and HTPnc categories, geopolymers are found to have higher impacts than OPC concretes. Similar results are obtained from FETP, FEP, METP, and MEP-where G-FA has the highest impact, followed by G-C, RAC, and NAC. 


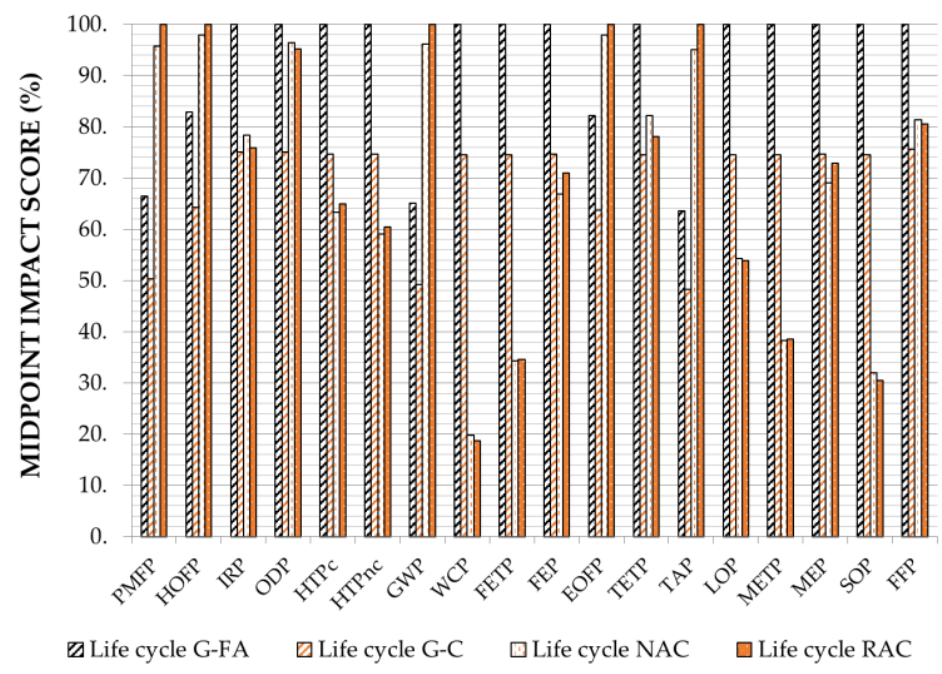

Figure 11. Midpoint impacts characterisation results.

Table 11 lists the midpoint assessment scores of the four investigated materials. An important result is observed in relation to WCP where geopolymers have remarkably high impacts on water consumption than OPC concretes. Consequently, high water requirement is observed for G-FA $\left(8.56 \mathrm{~m}^{3}\right)$ and G-C $\left(6.38 \mathrm{~m}^{3}\right)$, while NAC $\left(1.69 \mathrm{~m}^{3}\right)$ and RAC $\left(1.60 \mathrm{~m}^{3}\right)$ require from $54.8 \%$ (the smallest gap between G-C and NAC) to $81.3 \%$ (the largest gap between G-FA and RAC) less water consumption as seen in Figure 11. A similar result can be seen in LOP and SOP where in terms of LOP, G-FA (71.8 $\mathrm{m}^{2}$ a crop eq), and G-C (53.6 $\mathrm{m}^{2}$ a crop eq) occupied $20.3 \%$ to $46.1 \%$ more of land use over NAC ( $39.0 \mathrm{~m}^{2}$ a crop eq), followed by RAC ( $38.7 \mathrm{~m}^{2}$ a crop eq) as seen in Figure 11. While in SOP category, G-FA (2.30 kg Cu eq) and G-C (1.71 kg Cu eq) have $42.7 \%$ to $62.5 \%$ more impacts than NAC ( $0.733 \mathrm{~kg} \mathrm{Cu} \mathrm{eq)} \mathrm{and} \mathrm{RAC} \mathrm{(0.70} \mathrm{kg} \mathrm{Cu} \mathrm{eq).}$

Table 11. Midpoint impacts scores for each material.

\begin{tabular}{|c|c|c|c|c|c|}
\hline Damage Category & Unit & G-FA & G-C & NAC & RAC \\
\hline PMFP & kg PM2.5 eq & 0.830 & 0.628 & 1.200 & 1.250 \\
\hline HOFP & $\mathrm{kg} \mathrm{NO}_{x} \mathrm{eq}$ & 2.03 & 1.58 & 2.40 & 2.45 \\
\hline IRP & $\mathrm{kBq}$ Co-60 eq & 8.32 & 6.24 & 6.52 & 6.31 \\
\hline ODP & $\mathrm{kgCFC}_{11} \mathrm{eq}$ & 0.000217 & 0.000163 & 0.000209 & 0.000207 \\
\hline НTPс & $\mathrm{kg} 1,4-\mathrm{DCB}$ & 18.40 & 13.80 & 11.70 & 12.00 \\
\hline HTPne & kg 1,4-DCB & 551 & 411 & 325 & 333 \\
\hline GWP & $\mathrm{kgCO}_{2} \mathrm{eq}$ & 477 & 360 & 704 & 732 \\
\hline WCP & $\mathrm{m}^{3}$ & 8.56 & 6.38 & 1.69 & 1.60 \\
\hline FETP & kg 1,4-DCB & 25.70 & 19.20 & 8.79 & 8.89 \\
\hline FEP & $\mathrm{kg} P$ eq & 0.196 & 0.147 & 0.131 & 0.139 \\
\hline EOFP & $\mathrm{kg} \mathrm{NO}_{\mathrm{y}} \mathrm{eq}$ & 2.06 & 1.60 & 2.45 & 2.51 \\
\hline TETP & $\mathrm{kg} 1,4-\mathrm{DCB}$ & $3.75 \mathrm{E} 3$ & $2.8 \mathrm{E} 3$ & $3.08 \mathrm{E} 3$ & $2.93 \mathrm{E} 3$ \\
\hline TAP & $\mathrm{kg} \mathrm{SO}_{2} \mathrm{eq}$ & 2.10 & 1.60 & 3.14 & 3.31 \\
\hline LOP & $\mathrm{m}^{2} \mathrm{a}$ crop eq & 71.8 & 53.6 & 39 & 38.7 \\
\hline METP & $\operatorname{kg~} 1,4-\mathrm{DCB}$ & 34.9 & 26 & 13.4 & 13.4 \\
\hline MEP & $\mathrm{kg} \mathrm{Neq}$ & 0.0127 & 0.00945 & 0.00874 & 0.00922 \\
\hline SOP & $\mathrm{kgCu}$ eq & 2.30 & 1.71 & 0.733 & 0.70 \\
\hline FFP & $\mathrm{kg}$ oil eq & 135 & 102 & 110 & 109 \\
\hline
\end{tabular}

\subsection{Sensitivity Analysis}

Based on the transport scenario discussed in Table 5, a sensitivity analysis was conducted by using the IPCC 2013 GWP 100a and ReCiPe endpoint [60] assessment methods where the results are presented in Figures 12 and 13.

Figure 12 shows that the energy consumption associated with the transport of raw materials has negligible effects on the overall GWP. The difference observed is within $3.4 \%$ by which the $\mathrm{S} 1$ releases approximately $16.1 \mathrm{~kg}$ more $\mathrm{CO}_{2}$ as compared to the main case analysis. In terms of S2, the G-FA has higher impacts than the main case by $19.7 \%$. Looking at the distances listed in Table 5, the difference between the main case and S1 is $254 \mathrm{~km}$, while the S2 is $350 \mathrm{~km}$ more than the main case. It appears that the transportation 
of raw materials increases GWP by $0.013 \%$ for each kilometer while transporting to the construction site and disposal site; each kilometer will result in a $0.056 \%$ difference.

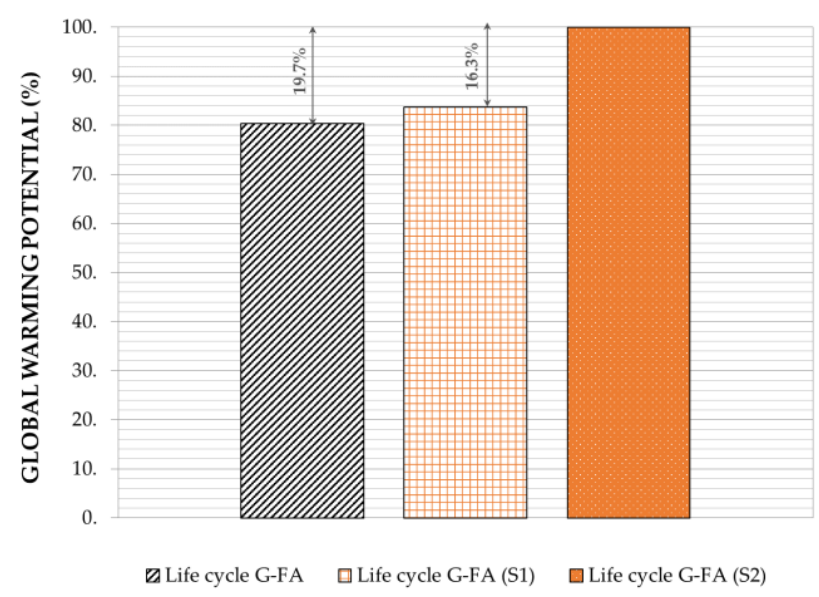

Figure 12. Sensitivity analysis of transport scenarios by IPCC GWP 100a.

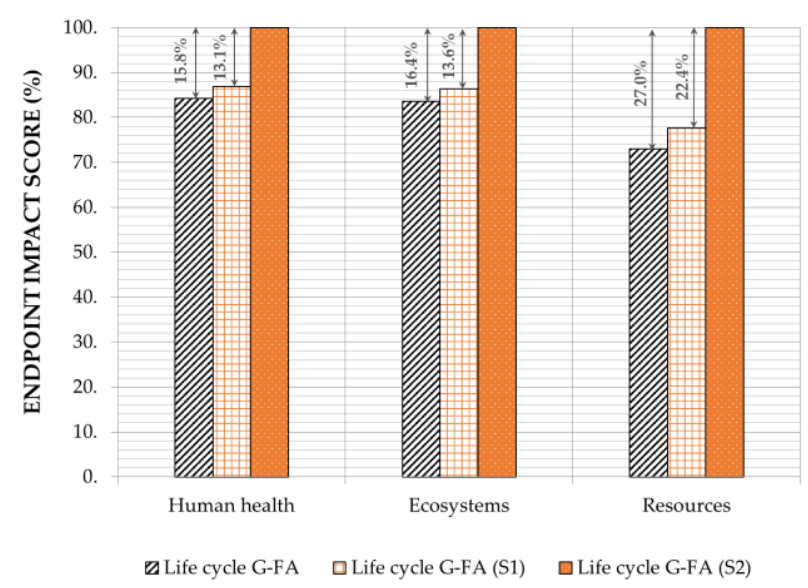

Figure 13. Sensitivity analysis of transport scenarios by endpoint assessment.

From the endpoint assessment results in Figure 13, the S1 entails higher environmental impacts in three categories as compared to the main scenario. The impacts change ranges from $2.7 \%$ to $4.6 \%$ in the three damage categories. However, the S2 (where the distances of transporting the material and waste concrete were doubled) exhibits remarkably high impacts that $15.8 \%$ to $27.0 \%$ of increment over main case impacts is observed.

\section{Discussion}

\subsection{Mechanical Performance}

Changing any variable affects the geopolymerisation process and its resultant microstructure. From previous studies $[37,41]$ the following general trends were observed for increased strength development:

- Higher GGBFS/FA ratio and reduced water content are known to affect the strength positively, while other variables like activator type and content, and binder type, can have variable effects.

- The strength of the material will increase accordingly, if it has a higher bulk density. Higher bulk density is reflected by the absence of pores/voids in the sample and by the material used.

- GGBFS has a smaller average particle size and a lower distribution of particle sizes (finer) compared to FA, and thus higher amounts of GGBFS should help in increasing the density of the material and its mechanical strength. 
Among the analysed geopolymers, the FA-based geopolymer establishes a remarkable mechanical performance when compared to ceno-based geopolymer, due to the hollow microstructure of cenospheres. As observed, cenospheres are hollow particles that reduce the overall weight of the material, and by introducing more inherent pores to the mortars have unavoidably decreased its mechanical strength. As a result, the G-FA's flexural strength and compressive strength are higher than those of the G-C. These findings suggest that a potential mix of geopolymer made of fly ash can be developed and optimised to obtain a structural material, while the geopolymer made of cenospheres can potentially be used for other applications as a lightweight material due to its low bulk density. Therefore, while it makes sense to compare the mechanical and environmental performance of G-FA, NAC, and RAC, being materials suitable for structural applications, a different approach should be investigated to compare the performance of G-C with other lightweight construction materials sharing similar applications.

\subsection{Global Warming Potential (GWP)}

The result indicates that the production of G-FA exhibits a lower GWP burden than OPC concretes by emitting $32.3 \%$ less GHGs $\left(473 \mathrm{~kg} \mathrm{CO}_{2}-\mathrm{eq}\right)$ as compared to the production of OPC made with natural aggregates $(699 \mathrm{~kg} \mathrm{CO}$-eq). While assessing their whole functional life, the observation is consistent with the results of previous studies regarding the geopolymer materials $[10,17,27]$. Throughout its functional life, the use of sodium silicates in geopolymers contributes $33.4 \%$ to the GWP, while the extraction of FA or cenospheres presents noticeable impacts up to $18.16 \%$. The reason for this finding is likely to be because the manufacture of the alkali activators $\left(\mathrm{Na}_{2} \mathrm{SiO}_{3}\right)$ is energy-intensive in nature, and the chemical reactions during their production involve huge carbon dioxide emissions. Based on the impact-allocation approach as detailed in the product stage subsection, the results also suggest that the extraction of FA and cenospheres is a crucial process that contributes to the environmental impacts of geopolymers. These may also indicate why G-C, which is lower in density, requires a lesser amount of sodium silicate and cenospheres than G-FA to produce the same functional unit of material and has contributed the least ( $357 \mathrm{~kg} \mathrm{CO}_{2}$-eq) to the GWP.

Comparing the OPC concretes, the cement is responsible for more than $66.9 \%$ of their total life-cycle impacts. The high contribution of cement has suggested that RAC, which requires a higher amount of cement to bind the recycled aggregates, has a higher burden (727 kg CO 2 -eq) on GWP than NAC.

\subsection{Endpoint Assessment}

As observed, the life cycle of OPC concretes has the highest adverse impacts on the human health damage category $(\mathrm{HH})$. GHGs emissions and energy consumption of $1.8 \mathrm{GJ} /$ tones during the manufacturing of cement is the main reason for the high negative impacts of OPC concretes [24]. This has explained that the production of geopolymers that does not involve the manufacture of cement has a reduction of $23.7 \%$ (G-FA) to $41.6 \%(\mathrm{G}-\mathrm{C})$ over NAC. However, the fusion of soda ash and silica sand during the production of sodium silicate adversely affected several indicators such as carcinogens, ionising radiation, and ozone layer depletion [62], resulting in non-negligible negative impacts of geopolymer on the $\mathrm{HH}$. Human toxicity is found to be one of the key environmental impacts of geopolymer other than global warming [27].

Concerning the ecosystem quality damage category (EQ), the functional life of OPC concretes presented $12.3 \%$ to $33.2 \%$ more damage than those of geopolymers. This can be explained by the cement production that utilises high energy-consuming machinery leading to a large number of harmful emissions to terrestrial, freshwater, etc., that disturb the ecosystem [24]. Geopolymer does not require cement, causing lesser damage to the EQ, with G-C exhibiting the least impact. This finding is credibly due to the lesser amount of the ingredients used to produce G-C and hence, lesser impacts are associated with the production of $1 \mathrm{~m}^{3}$ of G-C than of G-FA. 
The damage to the resources damage category (RD) during the functional life of G-FA is higher than that of the two OPC concretes and G-C. It can be explained by the great negative impacts of alkali activator to the RD [62] due to the utilisation of sodium chloride, water, sodium carbonate, silica sand, furnace oil, and electricity during the preparation of $\mathrm{Na}_{2} \mathrm{SiO}_{3}$ [15]. Eventually, the functional life of OPC concrete that does not involve sodium silicate production causes $15.6 \%$ to $42.3 \%$ less damage to RD than the geopolymer.

\section{Identification of Contributing Factors}

As shown in Figure 6, the majority of the negative impacts from G-FA are caused by the alkaline activator, sodium silicate and mostly on $\mathrm{HH}$. As observed, $\mathrm{Na}_{2} \mathrm{SiO}_{3}$ contributes $45.6 \%$ of impacts to the functional life of G-FA. This observation agrees with the reported results by Salas et al. [15] whereby sodium silicate production emits a considerable quantity of GHGs and pollutes the surrounding water system due to the disposal of wastewater [24]. Other important observations are the effects of FA and cenospheres on the environmental impacts. In this analysis, the economic allocation procedure was used in a way that a partial load from the primary production impacts was allocated to their waste, such as FA and cenospheres, that were used to produce G-FA and G-C. As a result, high environmental loads $(25.2 \%)$ from the FA and cenospheres are observed and this can be explained by the production system from coal power plants that emit large quantities of airborne pollutants such as $\mathrm{CO}_{2}, \mathrm{NO}_{2}$, and $\mathrm{SO}_{2}$, etc. The finding suggests that after impact allocation, the byproducts can result in a significant contribution to the overall negative impacts of the geopolymer life cycle.

Considering the OPC concretes, cement is responsible for $83.4 \%$ to $85.1 \%$ of environmental impacts and $\mathrm{HH}$ is the most affected category. This is due to the high pollutant emission mining activity of the calcareous and argillaceous materials and the manufacturing of cement in the plant [24]. This finding supports that the reduction of the use of cement can be the most efficient solution to mitigate the environmental impacts by OPC concretes.

\subsection{Midpoint Assessment}

In the midpoint level assessment, G-FA presents higher impacts in IRP over OPC concretes. It suggests that the involvement of the electrolysis process in the manufacturing of sodium silicate will increase the adsorption of ionised radiation and decrease the stratospheric ozone [24], which are causally linked to the incidents of various cancer diseases [60]. However, OPC concretes present similar impacts as G-FA in ODP because the calcination of limestone in a kiln at high temperatures will release carbon dioxide waste [28].

In human toxicity and ecotoxicity categories, geopolymers show higher impacts than OPC concretes. This is mainly attributed to the chemical reaction during sodium silicate production, which releases 1,4-DCB to the air and produces contaminated water that will pollute the water bodies [24], including fresh waters and marine water. OPC concretes have smaller impacts on ecotoxicity due to the absence of an alkaline activator during its life cycle. However, it is observed that the production of cement will also cause substantial pollution to the natural soils due to the heat production in the coke furnace.

It is known that the concrete-making process involves a considerable quantity of water use; however, the treatment of byproducts such as blast furnace slag and fly ash require a more significant amount of water. Consequently, high water demand is observed for geopolymers by consuming $54.8 \%$ to $81.3 \%$ more water during their life cycle. A similar trend is observed in eutrophication categories as the production of alkaline activator will dissolve inorganic nitrogen and phosphorous in waterbodies as well as the coal thermal power plant operation.

Concerning the soil quality, the result suggests that the use of cement has a large contribution to the acidification of soils and noticeable effects in fossil depletion due to the extraction of limestone and large fuel consumption in the production plant. However, the chemical reaction of sodium silicate and the production of GGBFS in the geopolymer life cycle will also substantially affect the ore grade. 


\subsection{Sensitivity Analysis}

In the sensitivity analysis presented in Section 3.5 appears that geopolymer will be affected to a greater extent due to the transportation of material and waste concrete than the transportation of raw materials in its life cycle. Observing Figure 11, an increment of raw materials transport distance by $254 \mathrm{~km}$ was found to impact geopolymers by $3.4 \%$ more, while increasing the transport distance of the mortar and disposing of the concrete by $350 \mathrm{~km}$ causes $19.7 \%$ more impact. A similar trend was observed in Figure 12 that S1 entails $2.7 \%$ to $4.6 \%$ more impact than the main case while S2 entails $15.8 \%$ to $27.0 \%$ more impact than the main case in three categories.

Collectively, it presents a finding that the environmental impacts are critically affected not only by the transport distance of the materials, but also the density of the materials due to the proportional relationships between the weight, distance, and transport energy consumption. In this study, the transport distance of mortar or concrete was found to deal with higher impacts than the transport distance of raw materials, by which token the raw materials that are lightweight do not exhibit the same impact on the environmental burdens of G-FA. This is contrary to the findings that the transportation of raw materials is the greater cause of the environmental burdens by the geopolymers.

In the present research, $60 \%$ of fronthaul distances were estimated for backhaul transportation. This approach and its findings support the transport of raw materials, such as fly ash, that can be extended to greater distances, and the geopolymer still exhibits high sustainability in its life cycle [63]. The density of materials is the key factor to reduce the transportation impacts from geopolymers, and it is very much a key component in future attempts to improve the transportation schemes of geopolymer life cycle in order to resolve the environmental burdens of geopolymers.

\section{Conclusions}

In this work, the mechanical properties of two geopolymers, FA-based and ceno-based geopolymers, and their sustainability performance based on a cradle-to-grave assessment were presented. In summary, two geopolymer mortar mixes were developed and the key factors that contribute to the environmental burdens by the entire geopolymer life cycle were studied. The contribution of this work is the development of two geopolymers that can be potential substitutions of conventional concretes with moderate compressive strength (i.e., 20 to $65 \mathrm{MPa}$ after 28 days of curing) and the identification of factors that can contribute to the future development of a sustainable geopolymer mix.

Flexural and compressive strength testing were used to examine the mechanical properties of the geopolymers. It was observed that the FA-based geopolymer demonstrated high compressive and flexural strength over ceno-based geopolymer due to the hollow microstructure of cenospheres that introduce more inherent pores to the material-hence reducing its mechanical strength. The flexural strength and compressive strength of FA-based geopolymer were $6.03 \mathrm{MPa}$ and $64.56 \mathrm{MPa}$, respectively, while the same properties for cenobased geopolymer were $3.13 \mathrm{MPa}$ and $19.09 \mathrm{MPa}$. This result showed that cenospheres, as hollow particles, induce a high reduction to the overall material weight and the mechanical strength of the geopolymer. This result encourages us to investigate this material for different lightweight applications. To facilitate the transition toward a more sustainable, energy-efficient, and comfortable built environment and contribute to an effective circular economy in the building sector, the materials could be further investigated and optimised for building envelope applications. Additionally, its environmental impact should be compared with commonly used lightweight construction materials having, among other, similar thermal and acoustic performance.

Concerning the sustainability performance, the geopolymer entailed advantages over OPC concretes on global warming potential, but it exhibited significant environmental damages such as high-water consumption and causes to ecotoxicity. Amongst the factors that contributed to the environmental damages, alkali activator and fly ash were found to be the major components that entailed the impacts. $\mathrm{Na}_{2} \mathrm{SiO}_{3}$ contributes $45.6 \%$ of impacts 
to the functional life of FA-based geopolymer, while $25.2 \%$ of impacts result from the industrial byproducts (i.e. fly ash and cenospheres). From the perspective of long-term development for geopolymer, these components should be given special attention to ensure the sustainability advantages of geopolymer in the building sector. Future studies should focus on exploring the greener alternatives for sodium silicate as an alkali activator (e.g., using renewable energy in its energy-intensive production process) and a more productive way to abstract the byproducts such as fly ash, cenospheres, and GGBFS from their main production. Besides the density of the materials, researchers should also consider the transportation mode, such as sea freight, in order to improve the sustainability of the geopolymer life cycle.

Supplementary Materials: The following are available online at https: / www.mdpi.com/article / 10.3390/su132011167/s1, Figure S1: Volume density against particle size distribution of the industrial byproduct materials, Figure S2: Scanning electron microscopy (SEM) images of the pure hollow cenospheres used in this study, Table S1: Inventories for energy/fuel, Table S2: Inventories for transport.

Author Contributions: Conceptualization, W.T., G.P. and S.M.E.S.; methodology W.T., G.P. and S.M.E.S.; validation, W.T., G.P. and S.M.E.S.; formal analysis, W.T.; investigation, W.T. and G.P.; resources, G.P.; data curation, W.T. and G.P.; writing-original draft preparation, W.T.; writingreview and editing, W.T., G.P. and S.M.E.S.; visualization, W.T. and G.P.; supervision, G.P. and S.M.E.S.; project administration, G.P.; funding acquisition, G.P. All authors have read and agreed to the published version of the manuscript.

Funding: This research was funded by UNSW Materials and Manufacturing Future Institute (MMFI) under the MMFI Seed Fund Research.

Institutional Review Board Statement: Not applicable.

Informed Consent Statement: Not applicable.

Data Availability Statement: The data presented in this study are openly available in Mendeley Data at doi:10.17632/prxw4fj757.1.

Acknowledgments: The authors would like to show their appreciation and acknowledgment to UNSW Material and Manufacturing Future Institute for their support. The authors acknowledge Charles Sorrell, Pramod Koshy, Uttam Mittal, and Vincent Wong for the help and technical support provided during the development and characterization of the geopolymer.

Conflicts of Interest: The funders had no role in the design of the study; in the collection, analyses, or interpretation of data; in the writing of the manuscript, or in the decision to publish the results. The authors declare no conflict of interest.

\section{References}

1. Maddalena, R.; Roberts, J.; Hamilton, A. Can Portland cement be replaced by low-carbon alternative materials? A study on the thermal properties and carbon emissions of innovative cements. J. Clean. Prod. 2018, 186, 933-942. [CrossRef]

2. He, Z.; Zhu, X.; Wang, J.; Mu, M.; Wang, Y. Comparison of $\mathrm{CO}_{2}$ emissions from OPC and recycled cement production. Constr. Build. Mater. 2019, 211, 965-973. [CrossRef]

3. Assi, L.; Carter, K.; Deaver, E.E.; Anay, R.; Ziehl, P. Sustainable concrete: Building a greener future. J. Clean. Prod. 2018, 198, 1641-1651. [CrossRef]

4. Davidovits, J. Geopolymers of the first generation: SILIFACE-Process. In Geopolymer '88, Proceedings of the First European Conference on Soft Mineralurgy, Compiegne, France, 1-3 June 1988; Geopolymer Institute: Saint Quentin, France, 1988; Volume 88, pp. 49-67.

5. Davidovits, J. Properties of geopolymer cements. In Proceedings of the First International Conference on Alkaline Cements and Concretes, Kiev, Ukraine, 11-14 October 1994; pp. 131-149.

6. Novais, R.M.; Pullar, R.; Labrincha, J. Geopolymer foams: An overview of recent advancements. Prog. Mater. Sci. 2020, 109, 100621. [CrossRef]

7. Aleem, M.A.; Arumairaj, P. Geopolymer concrete-A review. Int. J. Eng. Sci. Emerg. Technol. 2012, 1, 118-122. [CrossRef]

8. Wallah, S.; Rangan, B.V. Low-Calcium Fly Ash-Based Geopolymer Concrete: Long-Term Properties; Curtin University of Technology: Perth, Australia, 2006.

9. Zhuang, X.Y.; Chen, L.; Komarneni, S.; Zhou, C.H.; Tong, D.S.; Yang, H.M.; Yu, W.H.; Wang, H. Fly ash-based geopolymer: Clean production, properties and applications. J. Clean. Prod. 2016, 125, 253-267. [CrossRef] 
10. Pozzo, A.D.; Carabba, L.; Bignozzi, M.C.; Tugnoli, A. Life cycle assessment of a geopolymer mixture for fireproofing applications. Int. J. Life Cycle Assess. 2019, 24, 1743-1757. [CrossRef]

11. Cao, V.D.; Pilehvar, S.; Salas-Bringas, C.; Szczotok, A.M.; Bui, T.Q.; Carmona, M.; Rodriguez, J.F.; Kjøniksen, A.-L. Thermal performance and numerical simulation of geopolymer concrete containing different types of thermoregulating materials for passive building applications. Energy Build. 2018, 173, 678-688. [CrossRef]

12. Huseien, G.F.; Shah, K.W. Durability and life cycle evaluation of self-compacting concrete containing fly ash as GBFS replacement with alkali activation. Constr. Build. Mater. 2020, 235, 117458. [CrossRef]

13. Norton, M.G.; Provis, J.L. 1000 at 1000: Geopolymer technology-The current state of the art. J. Mater. Sci. 2020, 55, 13487-13489. [CrossRef]

14. Rasaki, S.A.; Bingxue, Z.; Guarecuco, R.; Thomas, T.; Minghui, Y. Geopolymer for use in heavy metals adsorption, and advanced oxidative processes: A critical review. J. Clean. Prod. 2019, 213, 42-58. [CrossRef]

15. Salas, D.A.; Ramirez, A.D.; Ulloa, N.; Baykara, H.; Boero, A. Life cycle assessment of geopolymer concrete. Constr. Build. Mater. 2018, 190, 170-177. [CrossRef]

16. Petrillo, A.; Cioffi, R.; De Felice, F.; Colangelo, F.; Borrelli, C. An environmental evaluation: A comparison between geopolymer and OPC concrete paving blocks manufacturing process in italy. Environ. Prog. Sustain. Energy 2016, 35, 1699-1708. [CrossRef]

17. Kastiukas, G.; Ruan, S.; Liang, S.; Zhou, X. Development of precast geopolymer concrete via oven and microwave radiation curing with an environmental assessment. J. Clean. Prod. 2020, 255, 120290. [CrossRef]

18. Teh, S.H.; Wiedmann, T.; Castel, A.; de Burgh, J. Hybrid life cycle assessment of greenhouse gas emissions from cement, concrete and geopolymer concrete in Australia. J. Clean. Prod. 2017, 152, 312-320. [CrossRef]

19. Dontriros, S.; Nooaek, P.; Supakata, N. Geopolymer Bricks from Concrete Residue and Palm Oil Fuel Ash: Evaluating Physicalmechanical Properties, Life Cycle Assessment and Economic Feasibility. EnvironmentAsia 2020, 13, 150-162.

20. Bumanis, G.; Vitola, L.; Pundiene, I.; Sinka, M.; Bajare, D. Gypsum, Geopolymers, and Starch-Alternative Binders for Bio-based Building Materials: A Review and Life-Cycle Assessment. Sustainability 2020, 12, 5666. [CrossRef]

21. Zhang, Z.; Provis, J.; Reid, A.; Wang, H. Mechanical, thermal insulation, thermal resistance and acoustic absorption properties of geopolymer foam concrete. Cem. Concr. Compos. 2015, 62, 97-105. [CrossRef]

22. Shahmansouri, A.A.; Nematzadeh, M.; Behnood, A. Mechanical properties of GGBFS-based geopolymer concrete incorporating natural zeolite and silica fume with an optimum design using response surface method. J. Build. Eng. 2021, 36, 102138. [CrossRef]

23. Wu, Y.; Lu, B.; Bai, T.; Wang, H.; Du, F.; Zhang, Y.; Cai, L.; Jiang, C.; Wang, W. Geopolymer, green alkali activated cementitious material: Synthesis, applications and challenges. Constr. Build. Mater. 2019, 224, 930-949. [CrossRef]

24. Bajpai, R.; Choudhary, K.; Srivastava, A.; Sangwan, K.S.; Singh, M. Environmental impact assessment of fly ash and silica fume based geopolymer concrete. J. Clean. Prod. 2020, 254, 120147. [CrossRef]

25. Passuello, A.; Rodríguez, E.D.; Hirt, E.; Longhi, M.; A Bernal, S.; Provis, J.; Kirchheim, A.P. Evaluation of the potential improvement in the environmental footprint of geopolymers using waste-derived activators. J. Clean. Prod. 2017, 166, 680-689. [CrossRef]

26. Peys, A.; Arnout, L.; Blanpain, B.; Rahier, H.; Van Acker, K.; Pontikes, Y. Mix-design Parameters and Real-life Considerations in the Pursuit of Lower Environmental Impact Inorganic Polymers. Waste Biomass Valoriz. 2017, 9, 879-889. [CrossRef]

27. Habert, G.; d'Espinose de Lacaillerie, J.; Roussel, N. An environmental evaluation of geopolymer based concrete production: Reviewing current research trends. J. Clean. Prod. 2011, 19, 1229-1238. [CrossRef]

28. Gomes, K.C.; Carvalho, M.; Diniz, D.D.P.; Abrantes, R.D.C.C.; Branco, M.A.; Junior, P.R.O.D.C. Carbon emissions associated with two types of foundations: CP-II Portland cement-based composite vs. geopolymer concrete. Matéria 2019, 24, 1-10. [CrossRef]

29. Ricciotti, L.; Occhicone, A.; Petrillo, A.; Ferone, C.; Cioffi, R.; Roviello, G. Geopolymer-based hybrid foams: Lightweight materials from a sustainable production process. J. Clean. Prod. 2020, 250, 119588. [CrossRef]

30. Yao, Y.; Hu, M.; Di Maio, F.; Cucurachi, S. Life cycle assessment of 3D printing geo-polymer concrete: An ex-ante study. J. Ind. Ecol. 2020, 24, 116-127. [CrossRef]

31. Hajimohammadi, A.; van Deventer, J.S.J. Characterisation of One-Part Geopolymer Binders Made from Fly Ash. Waste Biomass Valoriz. 2017, 8, 225-233. [CrossRef]

32. Yang, K.-H.; Song, J.-K.; Ashour, A.F.; Lee, E.-T. Properties of cementless mortars activated by sodium silicate. Constr. Build. Mater. 2008, 22, 1981-1989. [CrossRef]

33. Shobeiri, V.; Bennett, B.; Xie, T.; Visintin, P. A comprehensive assessment of the global warming potential of geopolymer concrete. J. Clean. Prod. 2021, 297, 126669. [CrossRef]

34. Salas, D.A.; Ramirez, A.D.; Rodriguez, C.; Petroche, D.M.; Boero, A.; Duque-Rivera, J. Environmental impacts, life cycle assessment and potential improvement measures for cement production: A literature review. J. Clean. Prod. 2016, 113, 114-122. [CrossRef]

35. Chen, C.; Habert, G.; Bouzidi, Y.; Jullien, A.; Ventura, A. LCA allocation procedure used as an incitative method for waste recycling: An application to mineral additions in concrete. Resour. Conserv. Recycl. 2010, 54, 1231-1240. [CrossRef]

36. McLellan, B.C.; Williams, R.; Lay, J.; van Riessen, A.; Corder, G.D. Costs and carbon emissions for geopolymer pastes in comparison to ordinary portland cement. J. Clean. Prod. 2011, 19, 1080-1090. [CrossRef]

37. Wong, V.; Jervis, W.; Fishburn, B.; Numata, T.; Joe, W.; Rawal, A.; Sorrell, C.C.; Koshy, P. Long-Term Strength Evolution in Ambient-Cured Solid-Activator Geopolymer Compositions. Minerals 2021, 11, 143. [CrossRef] 
38. Ecocem Pty Ltd. Product Data Sheet. Ecocem 20 February 2007. Rev 1. Available online: http://www.asms.com.au/uploads / 60 /eco004.pdf (accessed on 8 October 2021).

39. Envirospheres. Standard Hollow Ceramic Microspheres. E-SPHERES®ES Series 2018. Available online: https:/ / envirospheres. com.au/products/e-spheres-es-series/ (accessed on 8 October 2021).

40. Danish, A.; Mosaberpanah, M.A. Formation mechanism and applications of cenospheres: A review. J. Mater. Sci. 2020, 55, 4539-4557. [CrossRef]

41. Junaid, M.T.; Kayali, O.; Khennane, A.; Black, J. A mix design procedure for low calcium alkali activated fly ash-based concretes. Constr. Build. Mater. 2015, 79, 301-310. [CrossRef]

42. ASTM. C348-20. Standard Test Method for Flexural Strength of Hydraulic-Cement Mortars; ASTM International: West Conshohocken, PA, USA, 2020.

43. ASTM. C109/109M-20a. Standard Test Method for Compressive Strength of Hydraulic Cement Mortars (Using 2-in. or [50-mm] Cube Specimens); ASTM International: West Conshoshocken, PA, USA, 2020.

44. Ukritnukun, S.; Koshy, P.; Rawal, A.; Castel, A.; Sorrell, C.C. Predictive Model of Setting Times and Compressive Strengths for Low-Alkali, Ambient-Cured, Fly Ash/Slag-Based Geopolymers. Minerals 2020, 10, 920. [CrossRef]

45. International Organization for Standardization. ISO 14040:2006. Environmental Management-Life Cycle Assessment-Principles and Framework; International Organization for Standardization: Geneva, Switzerland, 2006.

46. International Organization for Standardization. ISO 14044:2006: Environmental Management-Life Cycle Assessment-Requirements and Guidelines, 1st ed.; International Organization for Standardization: Geneva, Switzerland, 2016.

47. Finkbeiner, M.; Inaba, A.; Tan, R.; Christiansen, K.; Klüppel, H.-J. The New International Standards for Life Cycle Assessment: ISO 14040 and ISO 14044. Int. J. Life Cycle Assess. 2006, 11, 80-85. [CrossRef]

48. Simapro. Available online: https:// simapro.com/ (accessed on 8 October 2021).

49. Etxeberria, M.; Vázquez, E.; Mari, A.; Barra, M. Influence of amount of recycled coarse aggregates and production process on properties of recycled aggregate concrete. Cem. Concr. Res. 2007, 37, 735-742. [CrossRef]

50. European Committee for Standardisation. EN 15804 (2013). EN 15804:2012 + A2:2019—Sustainability of Construction Works. Environmental Product Declarations. Core Rules for the Product Category of Construction Products; European Committee for Standardisation: Brussels, Belgium, 2019.

51. ALCAS. Feedback from the ALCAS on the GBCA: Life Cycle Assessment in Green Star. Discussion Paper. 2012. Available online: www.gbca.org.au/uploads/3/34051/ALCAS_GBCA_response_-20_Aug_FINALv3.pdf (accessed on 8 October 2021).

52. Albitar, M.; Ali, M.M.; Visintin, P.; Drechsler, M. Durability evaluation of geopolymer and conventional concretes. Constr. Build. Mater. 2017, 136, 374-385. [CrossRef]

53. Soh, W.M.; Tan, J.; Heng, J.; Cheeseman, C. Production of Cenospheres from Coal Fly Ash through Vertical Thermal Flame (VTF) Process. Mater. Sci. Forum 2016, 880, 7-10. [CrossRef]

54. Ranjbar, N.; Kuenzel, C. Cenospheres: A review. Fuel 2017, 207, 1-12. [CrossRef]

55. Marinković, S.; Radonjanin, V.; Malešev, M.; Ignjatović, I. Comparative environmental assessment of natural and recycled aggregate concrete. Waste Manag. 2010, 30, 2255-2264. [CrossRef]

56. Wernet, G.; Bauer, C.; Steubing, B.; Reinhard, J.; Moreno-Ruiz, E.; Weidema, B. The ecoinvent database version 3 (part I): Overview and methodology. Int. J. Life Cycle Assess. 2016, 21, 1218-1230. [CrossRef]

57. Kawai, K.; Sugiyama, T.; Kobayashi, K.; Sano, S. Inventory Data and Case Studies for Environmental Performance Evaluation of Concrete Structure Construction. J. Adv. Concr. Technol. 2005, 3, 435-456. [CrossRef]

58. Zhu, P.; Hua, M.; Liu, H.; Wang, X.; Chen, C. Interfacial evaluation of geopolymer mortar prepared with recycled geopolymer fine aggregates. Constr. Build. Mater. 2020, 259, 119849. [CrossRef]

59. Cooper, J.S.; Woods, L.; Lee, S.J. Distance and backhaul in commodity transport modeling. Int. J. Life Cycle Assess. 2008, 13, 389-400. [CrossRef]

60. Huijbregts, M.; Steinmann, Z.; Elshout, P.; Stam, G.; Verones, F.; Vieira, M.; Hollander, A.; Zijp, M.; van Zelm, R. ReCiPe 2016 v1. 1 A Harmonized Life Cycle Impact Assessment Method at Midpoint and Endpoint Level Report I: Characterization; National Institute for Public Health and the Environment: Bilthoven, The Netherlands, 2017.

61. Adesina, A. Sustainable application of cenospheres in cementitious materials-Overview of performance. Dev. Built Environ. 2020, 4, 100029. [CrossRef]

62. Abbas, R.; Khereby, M.A.; Ghorab, H.Y.; Elkhoshkhany, N. Preparation of geopolymer concrete using Egyptian kaolin clay and the study of its environmental effects and economic cost. Clean Technol. Environ. Policy 2020, 22, 669-687. [CrossRef]

63. O'Brien, K.R.; Ménaché, J.; O’Moore, L.M. Impact of fly ash content and fly ash transportation distance on embodied greenhouse gas emissions and water consumption in concrete. Int. J. Life Cycle Assess. 2009, 14, 621-629. [CrossRef] 